\title{
RADIOCARBONO Y ESTADÍSTICA BAYESIANA: APORTACIONES A LA CRONOLOGÍA DE LA EDAD DEL BRONCE EN EL EXTREMO ORIENTAL DEL SUDESTE DE LA PENÍNSULA IBÉRICA
}

\begin{abstract}
La investigación arqueológica desarrollada en las últimas décadas ha permitido evaluar que en los valles de los ríos Segura y Vinalopó se dirimió el contacto entre dos sociedades de la Edad del Bronce de la península Ibérica: el grupo Argárico y el grupo del Prebético Meridional Valenciano. Las excavaciones realizadas en tres yacimientos de este ámbito-Terlinques, Cabezo Pardo y Cabezo Redondo-y las dataciones de radiocarbono obtenidas permiten por primera vez evaluar la diacronía del proceso histórico que envolvió el desarrollo de ambos grupos arqueológicos a lo largo del II milenio cal BC, así como determinar diversos momentos socialmente significativos en su devenir histórico. Para ello se ha construido un modelo estadístico de tipo bayesiano que incorpora a la estimación de las fechas calibradas la información de los contextos y la estratigrafía de las que fueron obtenidas.
\end{abstract}

Palabras clave: radiocarbono, cronología, estadística bayesiana, Edad del Bronce, El Argar, Bronce Valenciano.

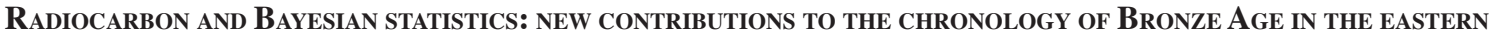 Iberian Peninsula}

Archaeological research carried out during the last decades has confirmed the contact between two Bronze Age societies in the Segura and Vinalopó valleys, namely the Argaric and the Valencian Southern Prebetic Groups both in the Iberian Peninsula. Recent excavations at three archaeological sites in this area-Terlinques, Cabezo Pardo and Cabezo Redondo- and their large radiocarbon series have allowed us to quantify the diachrony of the historical processes of both archaeological groups along the II millennium BC and determine several socially significant phases associated with their development. We do so by using Bayesian statistical methods to which we incorporate relevant contextual and stratigraphic information.

Key words: radiocarbon, chronology, Bayesian statistics, Bronze Age, El Argar, Valencian Bronze.

La cuestión cronológica sigue siendo uno de los principales problemas en el establecimiento de inferencias históricas efectuadas desde la práctica arqueológica. Durante buena parte del s. XX, la estratigrafía y la seriación tipológica permitieron ordenar un ingente registro arqueológico donde el "objeto" era la principal unidad de observación y análisis. Con la introducción del radiocarbono en la arqueología se produjo una auténtica "revolución" en la concreción cronológica de las culturas prehistóricas
(Renfrew 1973), pero la posibilidad de disponer de fechas desligadas de los juicios -y prejuicios- inherentes a la interpretación arqueológica de las tipologías generó un exceso de confianza en una técnica que todavía necesitaba ser mejorada.

Tras medio siglo de perfeccionamiento, algunos autores han señalado varios saltos cualitativos en su aplicación, que merecerían igualmente el calificativo de "revolucionarios" (Bayliss 2009). El más reciente ha sido 
la introducción de técnicas avanzadas en el tratamiento de datos, en el marco de la estadística bayesiana (Bronk Ramsey 2009; Williams 2012).

Las primeras aportaciones del radiocarbono al estudio de la Edad del Bronce en el cuadrante suroriental de la península Ibérica a inicios de la década de 1960 consistieron en fechar las etapas de división de los tiempos prehistóricos propuestos para cada zona (Jover y López 2009a). En los 1990, las series radiométricas efectuadas en yacimientos con dilatadas secuencias de ocupación permitieron proponer las primeras periodizaciones sobre las secuencias regionales y grupos arqueológicos (González Marcén 1994; Castro et al. 1996; Jover 1999). En los últimos años, los problemas asociados al tipo de muestra, desviación estándar o interpretación del contexto de procedencia ya vienen siendo contemplados (Lull et al. 2011; 2013a; 2013b; López Padilla 2011).

Con el presente trabajo pretendemos presentar un modelo para la determinación de la cronología y/o correlación cronológica de acciones o procesos de trabajo materializados en las secuencias arqueológicas, que permitan inferir cambios socialmente significativos en el desarrollo y organización del grupo argárico y de los grupos arqueológicos colindantes. Dicho modelo tiene como base el empleo de la estadística bayesiana en la estimación de las dataciones radiocarbónicas y supone una revalorización de la estratigrafía como herramienta de información cronológica en la interpretación histórica.

\section{DE ACCIONES HUMANAS SIMULTÁNEAS MATERIALIZADAS EN CONTEXTOS ARQUEO- LÓGICOS A EVENTOS CRONOLÓGICOS HIS- TÓRICAMENTE SIGNIFICATIVOS}

Sin fufa, El Argar es uno de los grupos arqueológicos peninsulares que mayor interés ha suscitado en la investigación (Lull 1983; Chapman 1991; Arteaga 2000; Lull et al. 2009; Molina y Cámara 2009). Su alto grado de desarrollo social ha justificado, para algunos autores, su consideración como una sociedad de clases (Arteaga 2000; Lull et al. 2009; 2011). Tras varias décadas de investigación centrada en el extremo septentrional del territorio de El Argar, venimos sosteniendo, a modo de hipótesis, que su desarrollo no puede entenderse completamente sin el análisis conjunto de las contradicciones sociales internas, resultantes de la oposición de intereses de grupo, y las externas, generadas como consecuencia de su contacto con el conjunto de sociedades que de forma coetánea se configuraron en su entorno (Jover y López 2004; 2009b). Una de las entidades sociales colindantes en su extremo septentrional fue el denominado grupo del Prebético meridional valenciano, tradicionalmente incluido en el área cultural del Bronce Valenciano (Jover 1999).

El estudio del proceso histórico que involucra las relaciones de El Argar con el Grupo del Prebético meridional valenciano ha constituido un aspecto esencial de nuestra investigación, pudiendo determinarse que ambas sociedades fueron contemporáneas y que, en buena medida, algunos cambios detectados en la segunda estuvieron estimulados por la primera (Jover y López 1997; 2004; 2009b). Además, hace ya tiempo que diversos autores señalaron la correlación cronológica que parecía observarse entre las series de dataciones radiocarbónicas del territorio argárico y las obtenidas en algunos yacimientos de Castilla-La Mancha y de Teruel (Fernández-Posse et al. 1996: 121; Burillo y Picazo 1997: 51), lo que podría indicar que el devenir histórico de todas estas zonas estuvo ligado.

Ahora bien, después de la experiencia transmitida y adquirida en el manejo y tratamiento de dataciones absolutas, tanto aisladas, como agrupadas en series radiométricas (Gónzalez Marcén 1994; Castro et al. 1996; Jover 1999; López Padilla 2011), debemos preguntarnos cómo concretar el tiempo de ocupación de los asentamientos y qué momentos en esa secuencia pudieron ser relevantes en el proceso histórico de la entidad social a la que pertenecieron. En definitiva, ¿cómo podemos determinar qué acciones o hechos, materializados en los contextos arqueológicos, son relevantes para concretar qué eventos cronológicos pudieron ser significativos en el proceso histórico de las entidades sociales en estudio?

Todo depósito arqueológico es el resultado de la acumulación de una multiplicidad de acciones y procesos de trabajo vivo efectuados por un grupo humano y desligado de su actividad (Bate 1998); pero también de procesos y eventos de muy variada naturaleza que transforman y alteran las condiciones y la naturaleza del contexto arqueológico y de los elementos que lo integran. Ningún contexto arqueológico es estático, ni será el resultado de un evento único (López Aguilar 1990). Por esta razón es tan importante determinar los procesos de formación y transformación de los yacimientos arqueológicos (Schiffer 1983; 1987), la calidad de información del contexto, así como concretar la (su) historia de deposición de unidades estratigráficas y de ocupación, a partir de la determinación de la secuencia de acciones y procesos de trabajo acumulados (Acosta 1999). 
Entre las que se pueden inferir arqueológicamente en cualquier asentamiento destacan las vinculadas con la fundación y construcción, uso y mantenimiento, y destrucción o abandono del mismo (Schiffer 1987). En muchas ocasiones pueden haber estado motivadas por necesidades puntuales del grupo humano que ocupó un asentamiento en particular, y que obligaron a labores de mantenimiento o reorganización de determinados espacios. En otras, en cambio, el reflejo de tales acciones en las secuencias de los yacimientos arqueológicos sí pueden ser indicadores de eventos con significación histórica, pero para ello es necesario que dicha acción de construcción o destrucción se haya producido de forma simultánea en diversos asentamientos de un mismo territorio y, con más motivo aún, si esta simultaneidad se constata en distintos espacios geográficos aledaños de una o varias entidades sociales. Cuantos más asentamientos muestren concordancia cronológica en un mayor espacio geográfico para una misma acción de fundación, construcción, destrucción o abandono definitivo, mayor relevancia histórica se podrá atribuir a dicho evento.

Acompañando dichas acciones de construcción/destrucción, también pueden registrarse otros cambios: en el patrón de ocupación del territorio, en la organización interna de los asentamientos, en las formas de producción o en la materialidad, en especial, en lo concerniente a mejoras en los medios de producción. Cuanto mayores y más diversos sean los cambios asociados a momentos de construcción o reconstrucción sincrónicos en el espacio, mayor trascendencia social habrá que considerar para dichos eventos (Beck et al. 2007).

Pero para determinar correctamente la cronología de estos eventos con significado histórico es imprescindible:

1. Disponer del registro arqueológico de varios asentamientos excavados en extensión, en los que se haya podido determinar los procesos de formación y transformación de cada uno de los depósitos arqueológicos en toda su secuencia.

2. Contar con una serie radiométrica amplia y bien distribuida en la estratigrafía de cada uno de los asentamientos, empleando muestras fiables y singulares que por su contexto y naturaleza informen directamente -e inequívocamente- de los momentos de construcción y destrucción/ abandono. Se trataría, por tanto, de disponer preferiblemente de muestras de vida corta, y en el número más amplio posible, puesto que a mayor cantidad de muestras datadas para cada acción, mayor precisión cronológica.
Así, a partir de las estratigrafías y las amplias series de dataciones radiocarbónicas obtenidas en los yacimientos de Cabezo Redondo ${ }^{1}$, Terlinques y Cabezo Pardo -únicos excavados en extensión y de los que es posible disponer actualmente de información arqueológica y dataciones de la calidad requerida- y a partir de la construcción de un modelo estadístico bayesiano para la estimación cronológica de los diferentes eventos de construcción, destrucción y abandono materializados en los tres asentamientos, consideramos que estamos en condiciones de dar los primeros pasos hacia la determinación de eventos cronológicos sincrónicos, asociados a cambios de diverso orden en la organización social, en diferentes territorios ocupados por el El Argar y los grupos del Prebético meridonal valenciano (Jover 1999) (fig. 1).

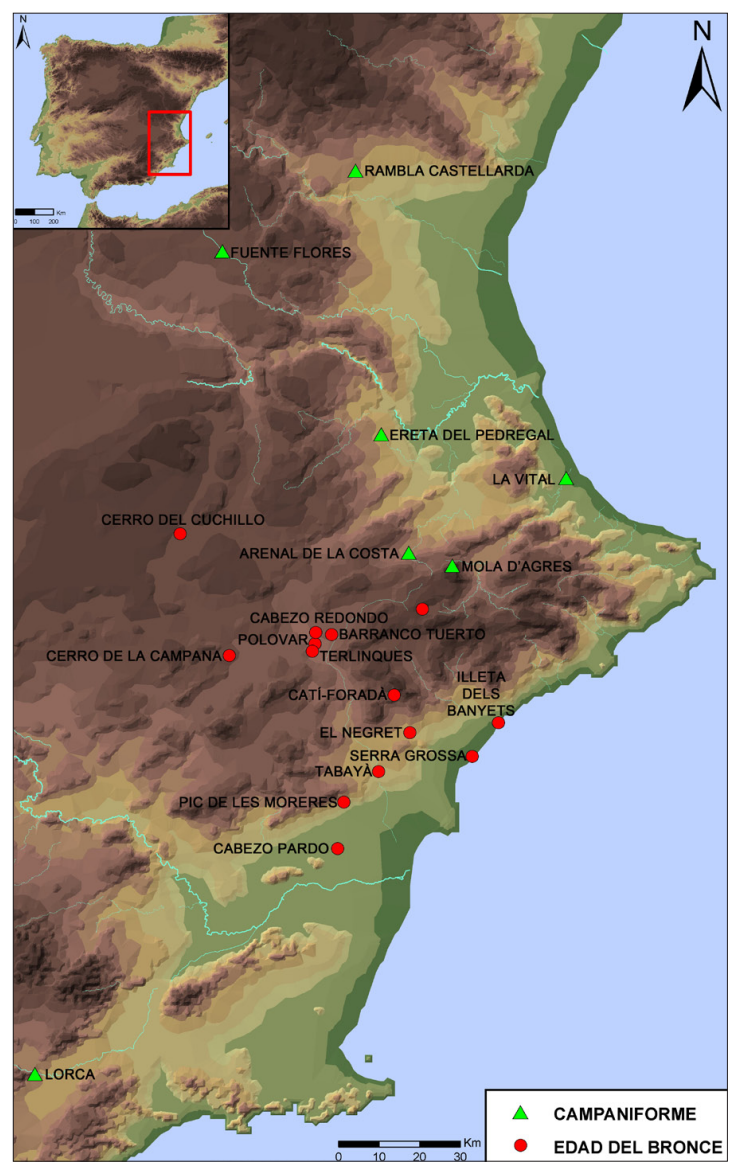

Fig. 1. Mapa de asentamientos con dataciones radiocarbónicas tratadas en el texto. 


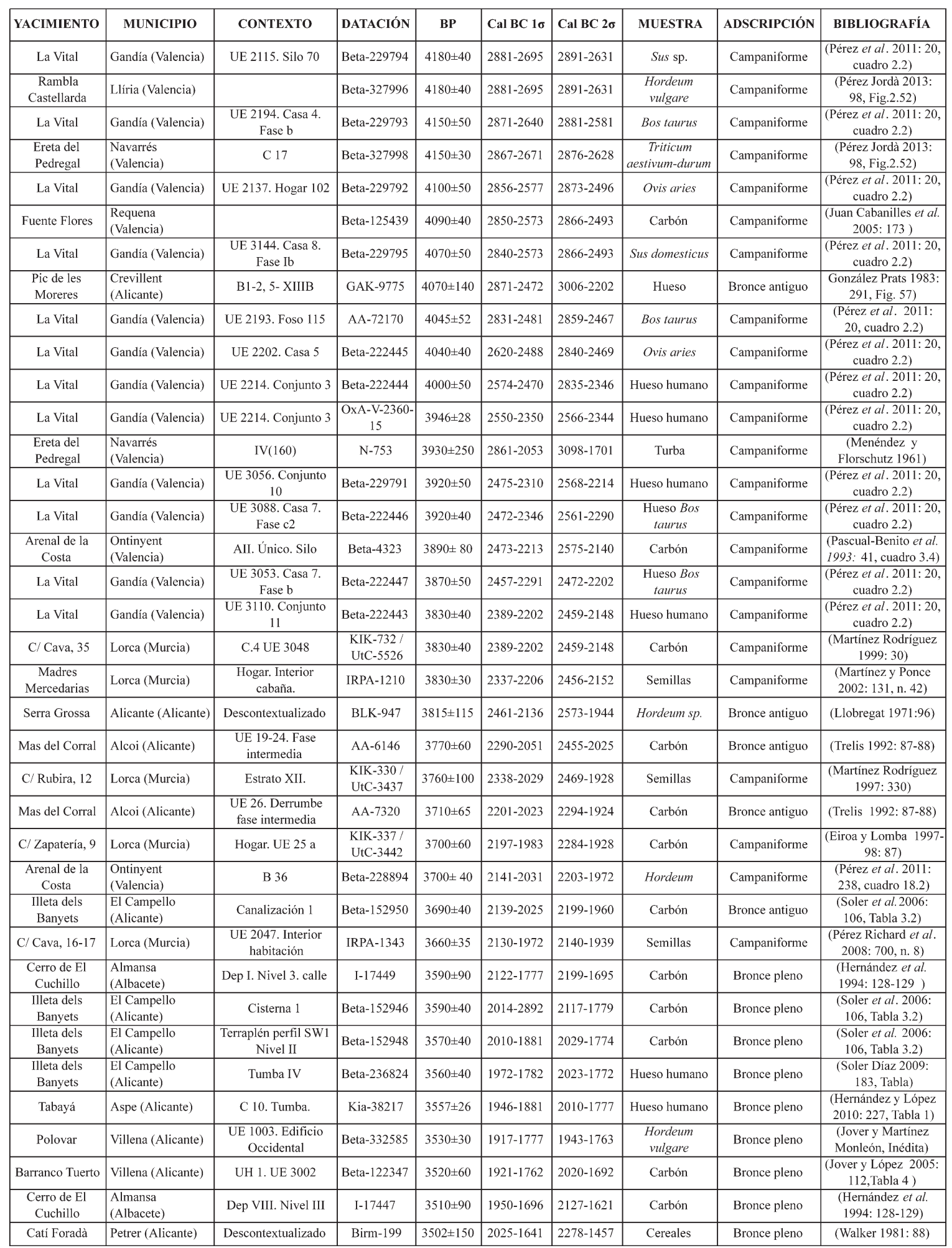


RAdiocarbono y estadística bayesiana: APORTACIONES A la CRONOLOGía de LA EDAD DEL BRONCE EN EL EXTREMO ORIENTAL DEL SUDESTE DE LA PENÍNSULA IBÉRICA

\begin{tabular}{|c|c|c|c|c|c|c|c|c|c|}
\hline YACIMIENTO & MUNICIPIO & CONTEXTO & DATACIÓN & BP & Cal BC $1 \sigma$ & Cal BC $2 \sigma$ & MUESTRA & ADSCRIPCIÓN & BIBLIOGRAFÍA \\
\hline $\begin{array}{l}\text { Cerro de El } \\
\text { Cuchillo }\end{array}$ & \begin{tabular}{|l|}
$\begin{array}{l}\text { Almansa } \\
\text { (Albacete) }\end{array}$ \\
\end{tabular} & $\begin{array}{l}\text { Dep IV. Cisterna. } \\
\text { Fase III. Bajo ent. }\end{array}$ & I-17488 & $3500 \pm 90$ & $1939-1695$ & 2124-1614 & Carbón & Bronce pleno & $\begin{array}{c}\text { (Hernández et } \\
\text { al.1994:128-129) }\end{array}$ \\
\hline Lloma Redona & $\begin{array}{l}\text { Monforte del Cid } \\
\text { (Alicante) }\end{array}$ & Relleno & ETH-10422 & $3500 \pm 60$ & $1897-1745$ & $2010-1667$ & Carbón & Bronce pleno & $\begin{array}{c}\text { (Gusi y Olària 1995: } \\
140 \text { ) }\end{array}$ \\
\hline $\begin{array}{c}\text { Illeta dels } \\
\text { Banyets }\end{array}$ & $\begin{array}{l}\text { El Campello } \\
\text { (Alicante) }\end{array}$ & Tumba III & Beta-240411 & $3500 \pm 40$ & $1883-1771$ & $1932-1696$ & Hueso humano & Bronce pleno & $\begin{array}{c}\text { (Soler Díaz 2009: } \\
\text { 183, Tabla) } \\
\end{array}$ \\
\hline $\begin{array}{c}\text { Illeta dels } \\
\text { Banyets }\end{array}$ & $\begin{array}{l}\text { El Campello } \\
\text { (Alicante) }\end{array}$ & tumba V & Beta-236822 & $3490 \pm 40$ & $1880-1764$ & 1918-1694 & Hueso humano & Bronce pleno & $\begin{array}{c}\text { (Soler Díaz 2009: } \\
\text { 183, Tabla) }\end{array}$ \\
\hline Tabayá & Aspe (Alicante) & C 11. Tumba & Beta-240409 & $3480 \pm 40$ & $1878-1749$ & $1900-1691$ & Ovis sp. & Bronce pleno & $\begin{array}{c}\text { (Hernández y López } \\
\text { 2010: 227, Tabla 1) }\end{array}$ \\
\hline $\begin{array}{l}\text { Cerro de El } \\
\text { Cuchillo }\end{array}$ & $\begin{array}{l}\text { Almansa } \\
\text { (Albacete) }\end{array}$ & $\begin{array}{l}\text { Dep V. Nivel II. } \\
\text { Leñero }\end{array}$ & $\mathrm{I}-17445$ & $3410 \pm 90$ & $1877-1616$ & 1938-1504 & Carbón & Bronce pleno & $\begin{array}{l}\text { (Hernández et al. } \\
\text { 1994: 128-129 ) }\end{array}$ \\
\hline $\begin{array}{l}\text { Cerro de El } \\
\text { Cuchillo }\end{array}$ & $\begin{array}{l}\text { Almansa } \\
\text { (Albacete) }\end{array}$ & Dep-. VI. Nivel I & I-17446 & $3390 \pm 90$ & $1871-1546$ & $1922-1465$ & Carbón & Bronce pleno & $\begin{array}{l}\text { (Hernández et al. } \\
\text { 1994: 128-129) }\end{array}$ \\
\hline $\begin{array}{c}\text { Illeta dels } \\
\text { Banyets }\end{array}$ & $\begin{array}{l}\text { El Campello } \\
\text { (Alicante) }\end{array}$ & Tumba III & Beta-188927 & $3390 \pm 40$ & $1741-1633$ & $1871-1560$ & Hueso humano & Bronce pleno & $\begin{array}{c}\text { (Soler et al. 2006: } \\
\text { 106, Tabla 3.2) }\end{array}$ \\
\hline $\begin{array}{c}\text { Illeta dels } \\
\text { Banyets }\end{array}$ & $\begin{array}{l}\text { El Campello } \\
\text { (Alicante) }\end{array}$ & Tumba IV & Beta-236823 & $3340 \pm 40$ & $1687-1560$ & $1739-1521$ & Hueso humano & Bronce pleno & $\begin{array}{c}\text { (Soler Díaz 2009: } \\
\text { 183, Tabla) }\end{array}$ \\
\hline Tabayá & Aspe (Alicante) & C 11. Tumba & Beta-240410 & $3340 \pm 40$ & $1687-1560$ & $1739-1521$ & Hueso humano & Bronce pleno & $\begin{array}{l}\text { (Hernández y López } \\
\text { 2010: 227, Tabla 1) }\end{array}$ \\
\hline $\begin{array}{l}\text { Cerro de la } \\
\text { Campana }\end{array}$ & Yecla (Murcia) & Pavimento. Nivel II & CSIC -450 & $3320 \pm 50$ & $1659-1530$ & $1741-1497$ & Cereal & Bronce pleno & $\begin{array}{c}\text { (Nieto y Clemente } \\
1983: 309)\end{array}$ \\
\hline EI Negret & Agost (Alicante) & $\begin{array}{c}\text { UE 1022. Nivel } \\
\text { intermedio UH } 2\end{array}$ & Beta-268985 & $3320 \pm 40$ & $1643-1532$ & $1691-1504$ & Hordeum & Bronce pleno & $\begin{array}{c}\text { (Barciela et al. 2012: } \\
127 \text {, fig. } 24 \text { ) }\end{array}$ \\
\hline $\begin{array}{c}\text { Illeta dels } \\
\text { Banyets }\end{array}$ & $\begin{array}{l}\text { El Campello } \\
\text { (Alicante) }\end{array}$ & Tumba III & Beta-236821 & $3320 \pm 40$ & $1643-1532$ & $1691-1504$ & Hueso humano & Bronce pleno & $\begin{array}{c}\text { (Soler 2009: 183, } \\
\text { Tabla) }\end{array}$ \\
\hline $\begin{array}{c}\text { Illeta dels } \\
\text { Banyets }\end{array}$ & $\begin{array}{l}\text { El Campello } \\
\text { (Alicante) }\end{array}$ & Tumba 1 & Beta-188925 & $3310 \pm 60$ & $1658-1512$ & $1741-1451$ & Hueso humano & Bronce pleno & $\begin{array}{c}\text { (Soler et al. 2006: } \\
\text { 106, Tabla 3.2) }\end{array}$ \\
\hline $\begin{array}{l}\text { Cerro de la } \\
\text { Campana }\end{array}$ & Yecla (Murcia) & Pavimento. Nivel II & CSIC-446 & $3310 \pm 50$ & $1641-1521$ & $1736-1460$ & Cereal & Bronce pleno & $\begin{array}{c}\text { (Nieto y Clemente } \\
1983: 309 \text { ) }\end{array}$ \\
\hline $\begin{array}{c}\text { Cerro de la } \\
\text { Campana }\end{array}$ & Yecla (Murcia) & Poste. Nivel II & CSIC- 445 & $3310 \pm 50$ & $1641-1521$ & $1736-1460$ & Carbón & Bronce pleno & $\begin{array}{c}\text { (Nieto y Clemente } \\
1983: 309 \text { ) }\end{array}$ \\
\hline $\begin{array}{c}\text { Cerro de la } \\
\text { Campana }\end{array}$ & Yecla (Murcia) & Pavimento. Nivel II & CSIC- 448 & $3300 \pm 50$ & $1628-1514$ & $1728-1454$ & Cereal & Bronce pleno & $\begin{array}{c}\text { (Nieto y Clemente } \\
1983: 309 \text { ) }\end{array}$ \\
\hline $\begin{array}{c}\text { Illeta dels } \\
\text { Banyets }\end{array}$ & $\begin{array}{l}\text { El Campello } \\
\text { (Alicante) }\end{array}$ & Cisterna 1 & Beta-152947 & $3270 \pm 40$ & $1610-1504$ & $1632-1449$ & Carbón & Bronce pleno & $\begin{array}{c}\text { (Soler et al. } 2006: \\
\text { 106, Tabla 3.2) }\end{array}$ \\
\hline El Negret & Agost (Alicante) & $\begin{array}{c}\text { UE 1014. Abandono } \\
\text { UH } 2\end{array}$ & Beta-268983 & $3150 \pm 40$ & $1495-1326$ & $1505-1301$ & $\begin{array}{c}\text { Diafisis } \\
\text { mesomamífero }\end{array}$ & Bronce tardío & $\begin{array}{c}\text { (Barciela et al. 2012: } \\
127 \text {, fig. } 24 \text { ) }\end{array}$ \\
\hline El Negret & Agost (Alicante) & $\begin{array}{l}\text { UE 1019. Relleno } \\
\text { infrapuesto UH } 1\end{array}$ & Beta-268986 & $2970 \pm 50$ & $1268-1113$ & 1381-1022 & $\begin{array}{c}\text { Diafisis } \\
\text { mesomamifero }\end{array}$ & Bronce final I & $\begin{array}{c}\text { (Barciela et al. 2012: } \\
127 \text {, fig. } 24)\end{array}$ \\
\hline
\end{tabular}

Fig. 2 (página anterior y ésta). Relación de dataciones del ámbito geográfico en estudio, incluyendo su contexto y adscripción cultural y excluyendo las obtenidas en Cabezo Pardo, Terlinques y Cabezo Redondo.

LAS SERIES RADIOCARBÓNICAS DE LA EDAD DEL BRONCE EN EL BAJO SEGURA Y VINALOPÓ. EVALUACIÓN CRÍTICA DE LAS MUESTRAS Y DE LOS RESULTADOS

No cabe duda de que la datación radiocarbónica y su calibración dendrocronológica están permitiendo precisar cada vez más los intervalos en los que se enmarcan los procesos históricos que interesa inferir. Sin embargo, varias cuestiones impiden aún alcanzar plenamente este objetivo. En primer lugar, las elevadas desviaciones que registran muchas de las fechas disponibles, aspecto inherente al propio método físicoquímico que paulatinamente ha empezado a subsanarse; en segundo lugar, el tipo de muestras, preferentemente de vida larga, que se venían seleccionado hasta hace muy pocos años; y por último, la ostensible carencia de información publicada relativa al contexto arqueológico preciso de las muestras datadas y su naturaleza (Jover y López 2011).

Hace ya algún tiempo, A. Gilman (2003: 11) señalaba la consecuencia fundamental de estas carencias: las grandes dificultades que existen para proyectar los datos cronológicos obtenidos en ciertos yacimientos al resto del registro conocido del cuadrante sur-oriental de la península Ibérica, el cual en su inmensa mayoría procede de yacimientos que no cuentan con dataciones radiocarbónicas.

A principios del s. XXI, las tierras meridionales valencianas no constituían una excepción en este panorama. Sin embargo, en la última década se han documentado complejas secuencias de ocupación en varios asentamientos de la zona (fig. 2), en las que se reconocen varias fases arqueológicas delimitadas por momentos de construcción y destrucción superpuestos estratigráficamente. Éstas se acompañan de un número apreciable de dataciones absolutas que posibilitan, por primera vez, una tentativa de lectura 
Francisco Javier Jover Maestre, Juan Antonio López Padilla, GonZalo García-Donato Layrón

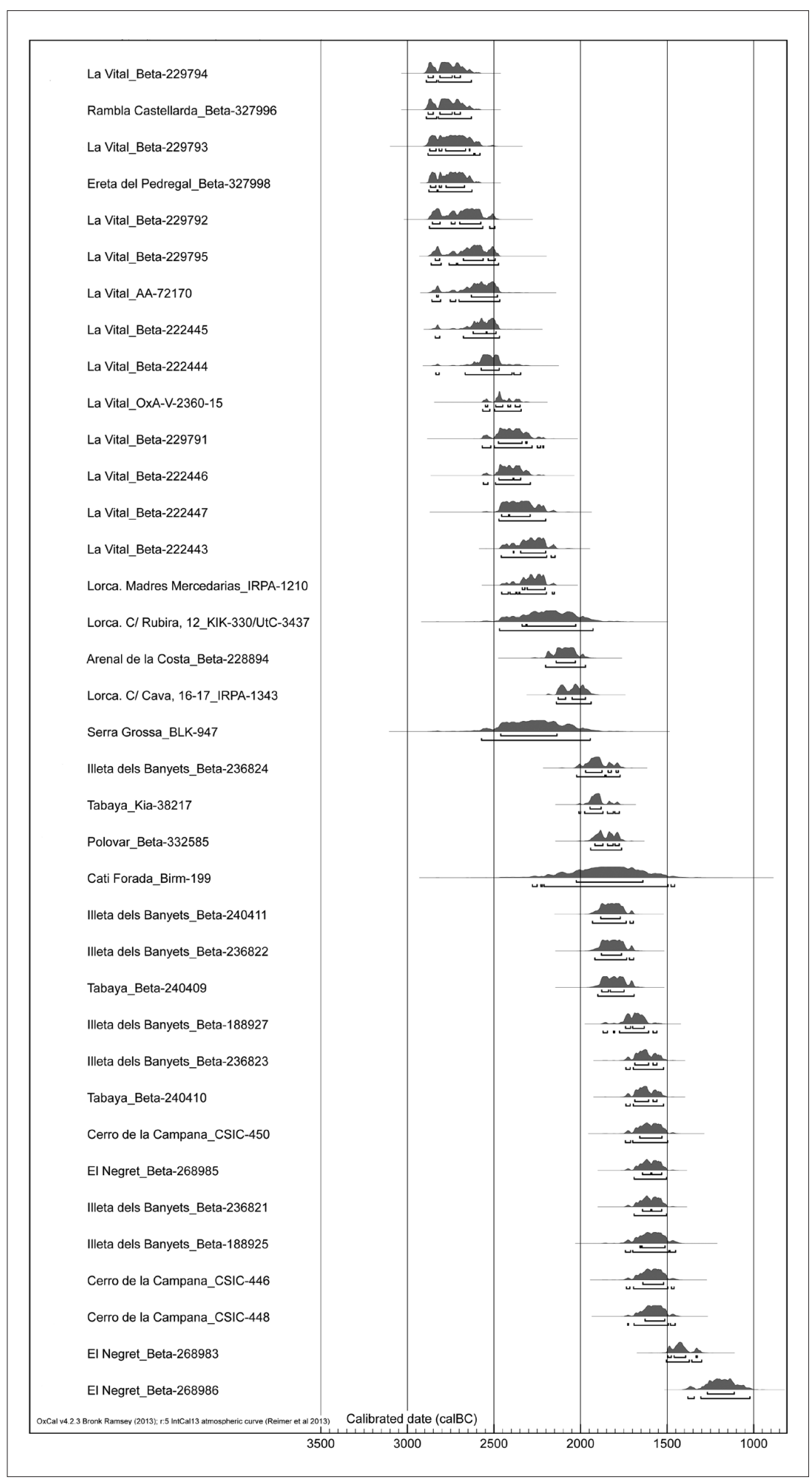

Fig. 3. Gráfico con las curvas de calibración de las dataciones obtenidas sobre muestras de vida corta del ámbito geográfico en estudio, excepto Cabezo Pardo, Terlinques y Cabezo Redondo. Programa OxCal v.4.2.3., según la curva atmosférica IntCal13 (Reimer et al. 2013). 
RAdiocarbono y estadística bayesiana: APORTACIONES A la CRONOLOGía de LA EDAD DEL BRONCE EN EL EXTREMO ORIENTAL DEL SUDESTE DE LA PENÍNSULA IBÉRICA

diacrónica del proceso histórico que involucró, al menos, a dos sociedades coetáneas -El Argar y el grupo del Prebético meridional valenciano (Jover 1999; López Padilla 2011)-, para las que ya se han propuesto y discutido los límites territoriales entre ambos (Jover y López 1997; 2009b). Esta nueva lectura está basada, por primera vez, en los datos proporcionados por los contextos, estratigrafías y muestras datadas de sus yacimientos, dejando en un segundo plano las series tipológicas que hasta hoy constituyeron los referentes fundamentales, si no los únicos.

Pero esto no significa que no resten aún considerables obstáculos que dificultan la observación y concreción del proceso en estudio. Entre otros, la escasez de dataciones en el levante peninsular para la fase arqueológica previa, identificada como campaniforme (Juan-Cabanilles 2005), sólo paliada en parte por la primera serie de dataciones de un yacimiento de esta cronología, obtenida en La Vital (Pérez et al. 2011: 235) y que esperamos pueda completarse pronto con los datos proporcionados por algunas excavaciones recientemente emprendidas ${ }^{2}$. Todas ellas muestran, en cualquier caso, su antecedencia con respecto a las series radiocarbónicas de los yacimientos que aquí nos ocupan (fig. 3).

\section{LA SERIE RADIOCARBÓNICA DEL ÁMBITO SEPTENTRIONAL ARGÁRICO}

A pesar de las dificultades que ha acarreado la definición del límite septentrional de la cultura de El Argar, éste ya ha sido delimitado, a modo de propuesta, en diversos trabajos a partir del reconocimiento de determinadas prácticas sociales, especialmente las funerarias, y la evidencia de objetos de tipología argárica en diversos contextos arqueológicos (Jover y López 1997; 2009b). Desafortunadamente no contamos con fechas de radiocarbono ni de San Antón ni de Laderas del Castillo, excavados en las primeras décadas del pasado siglo (Furgús 1937; Colominas 1936) ${ }^{3}$. Aparte de una datación de Pic de les Moreres (González Prats 1986) -desestimada por algunos autores (Castro et al. 1996: 31)- y de tres dataciones de enterramientos de Tabayá (Hernández 2009a) -alguna de ellas también un tanto contradictoria ${ }^{4}$ (Hernández y López 2010)-, las únicas series disponibles proceden de Cabezo Pardo e Illeta dels Banyets.

La serie de la Illeta dels Banyets perfila la cronología del extremo más lejano del oriente argárico. Cinco dataciones se asocian con niveles estratigráficos documentados,

\begin{tabular}{|c|c|c|c|c|c|c|}
\hline Ref. laboratorio & $\mathbf{U E}$ & Contexto & Fase arq. & Muestra & Descripción & Fecha BP \\
\hline Beta - 258468 & 1057 & \begin{tabular}{|l}
$\begin{array}{l}\text { Sobre pavimento } \\
\text { edificio E }\end{array}$ \\
\end{tabular} & 1 & Semillas & $\begin{array}{l}\text { Semillas de trigo y cebada } \\
\text { carbonizadas }\end{array}$ & $3530 \pm 40$ \\
\hline Beta -268980 & 1070 & $\begin{array}{l}\text { Sobre pavimento } \\
\text { edificio A }\end{array}$ & 1 & Hueso animal & $\begin{array}{c}\text { Mandíbula de ovicaprino de } \\
\text { edad juvenil (F-5) }\end{array}$ & $3500 \pm 40$ \\
\hline Beta - 268982 & 3017 & Pavimento edificio A & 1 & Hueso animal & $\begin{array}{c}\text { Mandíbula de ovicaprino de } \\
\text { edad juvenil }\end{array}$ & $3490 \pm 40$ \\
\hline Beta -308903 & 3017 & Pavimento edificio A & 1 & Hueso animal & Mandíbula de jabalí & $3590 \pm 30$ \\
\hline Beta - 268981 & 3017 & Pavimento edificio A & 1 & Hueso animal & Caparazón de tortuga & $3920 \pm 40$ \\
\hline Beta - 287332 & 1104 & Pavimento edificio $\mathrm{C}$ & 1 & Hueso animal & Costilla derecha de bóvido & $3620 \pm 40$ \\
\hline Beta - 308902 & 3005 & Pavimento edificio $\mathrm{J}$ & 2 & Hueso animal & Vértebra dorsal de bóvido & $3450 \pm 30$ \\
\hline Beta - 308904 & 3029 & Pavimento edificio L & 2 & Hueso animal & Mandíbula de suido & $3460 \pm 30$ \\
\hline Beta - 327334 & 3035 & Pavimento edificio $\mathrm{M}$ & 2 & Hueso animal & $\begin{array}{l}\text { Mandíbula de ovicaprino de } \\
\text { edad juvenil }\end{array}$ & $3350 \pm 40$ \\
\hline Beta -327335 & 1169 & Pavimento edificio $\mathrm{M}$ & 2 & Hueso animal & Costilla de ovicaprino adulto & $3450 \pm 30$ \\
\hline Beta -237765 & 8001 & $\begin{array}{l}\text { Tumba } 1 \text { (Individuo 1). } \\
\text { Edificio H }\end{array}$ & 2 & Hueso humano & Húmero derecho & $3460 \pm 40$ \\
\hline Beta - 237766 & 8001 & $\begin{array}{l}\text { Tumba } 1 \text { (Individuo 2). } \\
\text { Edificio H }\end{array}$ & 2 & Hueso humano & Húmero derecho & $3390 \pm 40$ \\
\hline Beta - 258466 & $1037=3005$ & Pavimento edificio $\mathbf{J}$ & 2 & Hueso animal & Costilla de ovicaprino (F-7) & $3440 \pm 40$ \\
\hline Beta - 292077 & 1120 & $\begin{array}{l}\text { Depósito bajo } \\
\text { pavimento UE } 3020 \text {, en } \\
\text { calle (P) }\end{array}$ & 3 & Hueso animal & $\begin{array}{c}\text { Mandíbula izquierda de } \\
\text { ovicaprino de edad juvenil }\end{array}$ & $3350 \pm 40$ \\
\hline Beta - 287333 & 1105 & Pavimento edificio $\mathrm{R}$ & 3 & Hueso animal & $\begin{array}{l}\text { Pelvis izquierda de ciervo } \\
\text { adulto }\end{array}$ & $3330 \pm 40$ \\
\hline Beta - 258467 & 3008 & Pavimento edificio $\mathrm{U}$ & 3 & Hueso animal & Costilla de bóvido & $3300 \pm 40$ \\
\hline
\end{tabular}

Fig. 4. Relación de dataciones de Cabezo Pardo, con indicación de su información contextual. 
mientras que el resto corresponde a enterramientos (Soler Díaz et al . 2006; 2009). Excepto éstas últimas, todas proceden de micromuestras sedimentarias extraídas de los testigos y perfiles, careciéndose de una información precisa de carácter contextual, lo que limita su utilidad a los efectos del objetivo planteado en este trabajo.

La serie de dataciones más amplia corresponde a Cabezo Pardo (López Padilla 2009). En la actualidad el número total de dataciones absolutas de este yacimiento es 19, de las cuales 17 pertenecen a contextos de la Edad del Bronce $^{5}$ (fig. 4). Todas se han obtenido de muestras de vida corta: dos de ellas -Beta-258468 y Beta-292078-de semillas carbonizadas de trigo y cebada; otras dos -Beta237765 y Beta-237766- de huesos humanos; y las trece restantes de huesos de diversas especies animales, localizados estratigráficamente en relación con pavimentos o suelos de ocupación (fig. 5).

Para el momento fundacional del asentamiento disponemos de las dataciones Beta-2689816 ${ }^{6}$, Beta-287332 y Beta-308903, todas provenientes de los rellenos de pavimentos de las casas o de las arcillas empleadas en la construcción de estructuras localizadas en su interior. Sobre los últimos suelos de estas viviendas se determinan evidencias claras de una destrucción súbita relacionada con un incendio. Disponemos de tres dataciones para fijar este evento -Beta-258468, Beta-268980 y Beta-268982.
Sobre los derrumbes de las estructuras de la fase anterior se levantaron los muros y pavimentos de las casas de la fase II. Éstas aparecen organizadas en torno a una calle que circunda lo que parece un gran edificio central. Las dataciones obtenidas para esta fase proceden, por una parte, de los enterramientos practicados en la tumba 1 -Beta-237765 y Beta-237766- y por otra, de varios fragmentos óseos localizados en el pavimento de tres de las unidades habitacionales -Beta258466, Beta-308902, Beta-308904, Beta-327334 у Beta-327335.

Las construcciones de la fase III se levantan sobre los derrumbes de la fase anterior, con viviendas cuyos muros cabalgan parcialmente las paredes de las casas más antiguas. Dos de las fechas disponibles para esta fase proceden de sendos rellenos de colmatación, por lo que están datando momentos de uso de los espacios en los que se depositaron. Una de ellas -Beta-292077- fue obtenida de un fragmento de hueso procedente del nivel de uso de la calle, mientras que la otra -Beta-287333- se tomó de los rellenos de nivelación del pavimento de una de las viviendas. La única fecha relacionada con el final de esta última fase de ocupación -Beta-258467- se obtuvo de un hueso de bóvido depositado sobre el piso de otra de las unidades habitacionales.

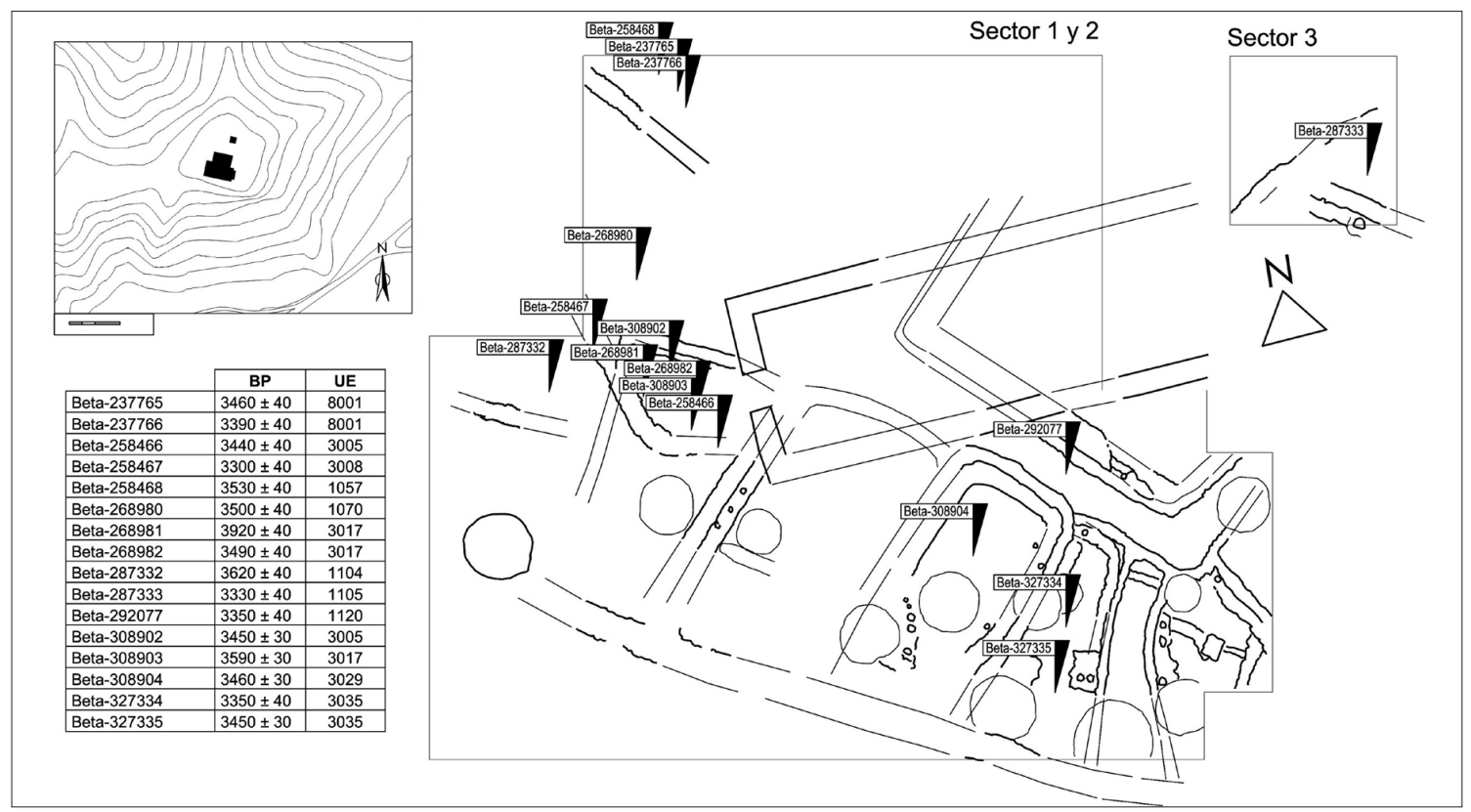

Fig. 5. Plano de Cabezo Pardo con la localización topográfica de las muestras datadas. 


\section{LA SERIE RADIOCARBÓNICA DEL PREBÉTICO MERIDIONAL VALENCIANO}

En el área del Prebético Meridional valenciano, ubicada al $\mathrm{N}$ del extremo septentrional de El Argar, se han documentado casi dos centenares de asentamientos cuya materialidad y prácticas sociales se alejan mucho de lo que reconocemos como argárico (Jover 1999). Este territorio ofrece uno de los mayores índices de yacimientos con fechas radiocarbónicas disponibles para la Edad del Bronce en las tierras valencianas, entre los que se encuentran los dos yacimientos con las series más amplias -Terlinques (López Padilla 2011) y Cabezo Redondo (Hernández 2009b; 2012). Con excepción de dos fechas de éste último, tomadas de sepulturas, todas proceden de contextos de habitación.
Son varios los asentamientos con una, dos, incluso cuatro dataciones, cuya información puede ser válida, pero de escasa utilidad para los fines aquí trazados. Es el caso de Barranco Tuerto (Jover y López 2005), Polovar? Lloma Redona (Gusi y Olària 1995), Mas del Corral (Trelis 1992), Serra Grossa (Llobregat 1971), Cerro de la Campana (Nieto y Clemente 1983) o Cerro de El Cuchillo (Hernández et al. 1994) (ver fig. 2). Problemas de diversa índole, como el tipo de muestra, la falta de información contextual o la desviación estándar, ya señaladas en otros trabajos (Hernández 1997; López Padilla 2011), aconsejan descartarlas.

Por otro lado, las recientes excavaciones llevadas a cabo en El Negret han evidenciado la existencia de al menos tres momentos de ocupación diferentes (Barciela

\begin{tabular}{|c|c|c|c|c|c|c|}
\hline Ref. Laboratorio & $\mathbf{U E}$ & Contexto & Fase arq. & Muestra & Descripción & Fecha BP \\
\hline $\mathrm{I}-4525$ & Dpto.I & Poste? & 1 & Carbón & Agregación de carbones & $3800 \pm 75$ \\
\hline Beta-240938 & 1016 & Desechos en relleno de construcción & 1 & $\begin{array}{l}\text { Hueso } \\
\text { animal }\end{array}$ & $\begin{array}{c}\text { Fragmento de vértebra de } \\
\text { ovicaprino }\end{array}$ & $3770 \pm 40$ \\
\hline Beta-189753 & 2016 & Poste. UH I. & 1 & Carbón & Carbón (Pinus halepensis) & $3750 \pm 60$ \\
\hline Beta-136171 & 1006 & Larguero de techumbre. UH I & 1 & Carbón & Carbón (Pinus halepensis) & $3630 \pm 60$ \\
\hline Beta-227373 & 1009 & Semillas almacenadas. UH I & 1 & Semillas & $\begin{array}{c}\text { Semillas de trigo (Triticum } \\
\text { durum) }\end{array}$ & $3680 \pm 40$ \\
\hline \multirow{2}{*}{ Beta-122343 } & \multirow{2}{*}{1009} & \multirow{2}{*}{ Semillas almacenadas. UH I } & \multirow{2}{*}{1} & \multirow{2}{*}{ Semillas } & Semillas de trigo y cebada & \multirow{2}{*}{$3640 \pm 70$} \\
\hline & & & & & (Triticum y Hordeum) & \\
\hline \multirow{2}{*}{ Beta-122344 } & \multirow{2}{*}{1009} & \multirow{2}{*}{ Semillas almacenadas. UH I } & \multirow{2}{*}{1} & \multirow{2}{*}{ Semillas } & Semillas de trigo y cebada & \multirow{2}{*}{$3530 \pm 60$} \\
\hline & & & & & (Triticum y Hordeum) & \\
\hline Beta-268988 & 1437 & Derrrumbe/Nivel de incendio & 1 & Semillas & Semillas de trigo (Triticum $\mathrm{sp}$ ) & $3640 \pm 40$ \\
\hline Beta-268989 & 1464 & Nivel de incendio & 1 & Semilla & $\begin{array}{c}\text { Semilla de trigo (Triticum } \\
\text { durum) }\end{array}$ & $3710 \pm 40$ \\
\hline Beta-268990 & 1485 & Nivel de incendio & 1 & Semillas & $\begin{array}{c}\text { Semillas de trigo (Triticum } \\
\text { durum) }\end{array}$ & $3600 \pm 40$ \\
\hline Beta-189756 & 1066 & Madero techumbre o viga. UH I & 2 & Carbón & Carbón (Pinus halepensis) & $3590 \pm 40$ \\
\hline Beta-136172 & 1006 & Larguero de techumbre. UH I & 2 & Carbón & Carbón (Pinus halepensis) & $3500 \pm 70$ \\
\hline Beta-240937 & 1372 & $\begin{array}{l}\text { Cereales carbonizados abandono UH } \\
\text { XIII }\end{array}$ & 2 & Semillas & $\begin{array}{c}\text { Semillas de trigo (Triticum } \\
\text { durum) }\end{array}$ & $3530 \pm 40$ \\
\hline Beta-189757 & 1066 & Estera o capazo desecho. UH I & 2 & $\begin{array}{c}\text { Esparto } \\
\text { carbonizado }\end{array}$ & $\begin{array}{c}\text { Esparto trenzado (Stipa } \\
\text { tenacissima) }\end{array}$ & $3420 \pm 80$ \\
\hline Beta-256351 & 1427 & $\begin{array}{l}\text { Estrato de derrumbe sobre pavimento } \\
\text { UH XI }\end{array}$ & 3 & $\begin{array}{c}\text { Hueso } \\
\text { animal } \\
\end{array}$ & Húmero de ovicaprino & $3450 \pm 40$ \\
\hline Beta-227574 & 1304 & Desecho sobre pavimento. UH X & 3 & $\begin{array}{c}\text { Hueso } \\
\text { animal }\end{array}$ & Diáfisis de bóvido (Bos taurus) & $3380 \pm 40$ \\
\hline Beta-190806 & 1076 & $\begin{array}{l}\text { Derrumbe techumbre y paredes. UH } \\
\text { VII }\end{array}$ & 3 & Carbón & Carbón (Pinus halepensis) & $3330 \pm 70$ \\
\hline Beta- 227575 & 1341 & Derrumbe techumbre y paredes. UH XI & 3 & Carbón & Carbón (Pinus halepensis) & $3310 \pm 40$ \\
\hline Beta-189754 & 1053 & Derrumbe techumbre y paredes. UH VI & 3 & Carbón & Carbón (Pinus halepensis) & $3300 \pm 60$ \\
\hline Beta-189758 & 1076 & Esparto trenzado desecho. UH VII & 3 & $\begin{array}{c}\text { Esparto } \\
\text { carbonizado }\end{array}$ & Esparto (Stipa tenacissima) & $3210 \pm 100$ \\
\hline
\end{tabular}

Fig. 6. Relación de las dataciones de Terlinques con indicación de su información contextual. 


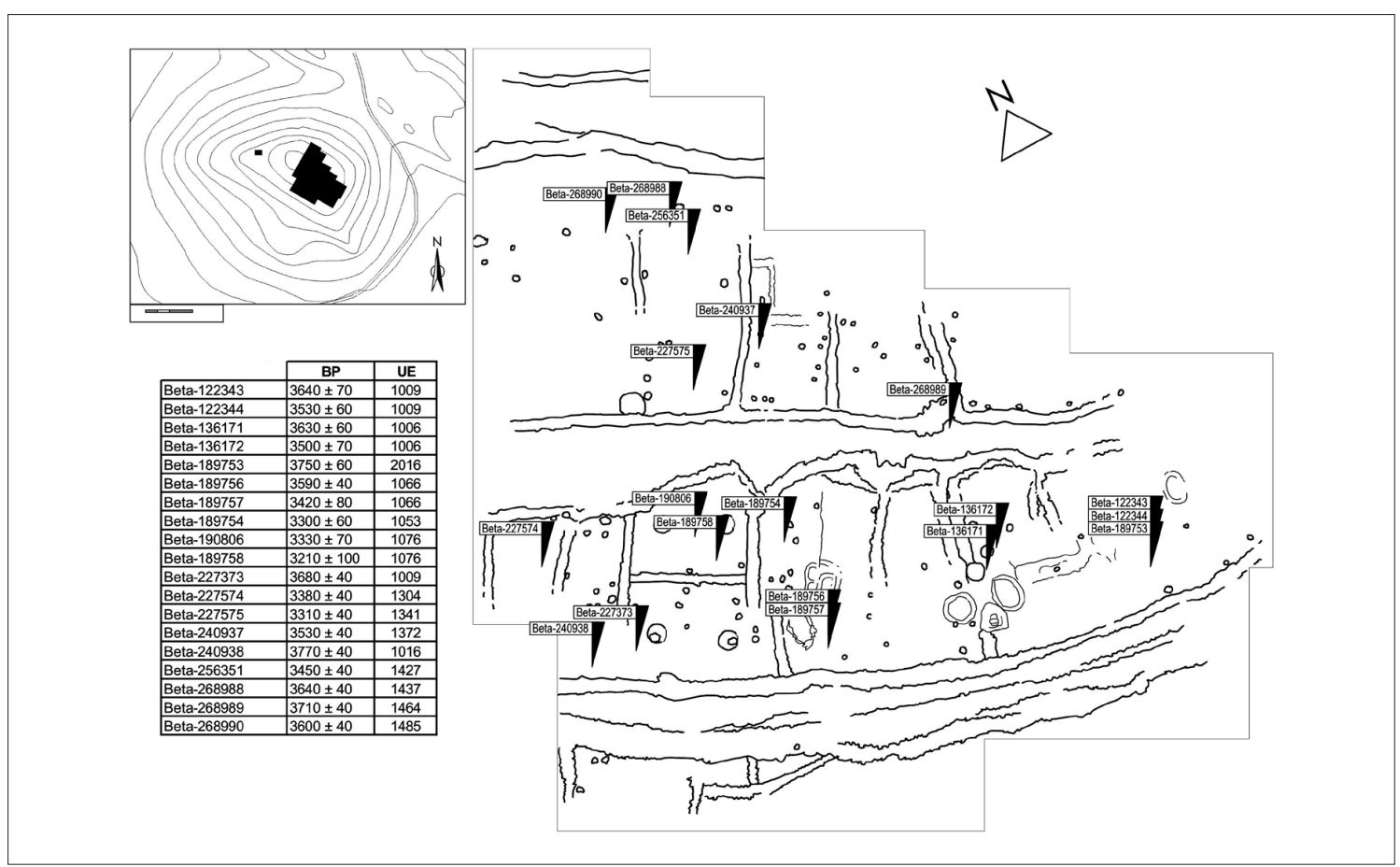

Fig. 7. Plano de Terlinques con la localización topográfica de las muestras datadas.

et al. 2012). Todas las dataciones proceden de muestras de vida corta, registradas en sendos niveles de incendio de la unidad habitacional 2, así como en el preparado de acondicionamiento del pavimento de la unidad habitacional 1.

La serie de Terlinques consta de 20 dataciones (fig. 6), de las cuales 19 se han obtenido en las excavaciones que se vienen realizando en el yacimiento desde 1998 (fig. 7). El inicio de la ocupación de Terlinques -fase Ise fija a partir de dos fechas procedentes de las unidades estratigráficas más antiguas. La fauna empleada en los rellenos de nivelación del pavimento -Beta-240938- y de los maderos empleados en la construcción de las viviendas de esta fase -Beta-136171 y Beta-189753- llevan el inicio del asentamiento a los siglos finales del III milenio cal BC. Esta fecha resulta coherente con la que proporcionara la fecha I-4525, tomada probablemente también de un poste y que fue la primera datación publicada de este yacimiento (Tarradell 1970; Soler y Fernández 1970). El final de esta primera fase de ocupación se relaciona con un buen número de dataciones sobre muestras de cereales carbonizados asociados o contenidos en capazos de esparto depositados o esparcidos sobre el pavimento. Dos de ellas -Beta-122343 y Beta-122344 provienen de las semillas contenidas en un mismo saco, y una tercera de cereales localizados a varios metros de distancia sobre el mismo pavimento -Beta-227373. Otras tres dataciones -Beta-268988, Beta-268989 y Beta268990- se tomaron también de semillas depositadas sobre el pavimento de otra unidad habitacional, estratigráficamente contemporánea y situada en la ladera septentrional del cerro. Todas ellas señalan con claridad un mismo horizonte cronológico para el incendio y destrucción del poblado al final de esta fase, pues las huellas del incendio pueden advertirse por todo el yacimiento.

Sobre los derrumbes de estas habitaciones se levantan las construcciones de la fase II, fechadas a partir de los anillos exteriores de dos fragmentos de maderos pertenecientes a las vigas de la techumbre o al sistema de sujeción de ésta. La única fecha relacionada con el final de esta segunda fase -Beta-189757- fue tomada de un resto de esparto depositado sobre el pavimento de una de las casas, al no documentarse semillas.

La fase III muestra una completa remodelación urbanística del asentamiento. Esta fase fija su cronología entre las fechas Beta-256351 y Beta-189758, tomadas de un resto óseo y de un fragmento de esparto, respectivamente. 
RAdiocarbono y estadística bayesiana: APORTACIONES A la CRONOLOGía de LA EDAD DEL BRONCE EN EL EXTREMO ORIENTAL DEL SUDESTE DE LA PENÍNSULA IBÉRICA

\begin{tabular}{|c|c|c|c|}
\hline Ref. Laboratorio & Contexto & BP & Muestra \\
\hline Beta-181406 & Departamento XIX. Poste. & $3420 \pm 60$ & Carbón \\
\hline Beta-181401 & Departamento XIX. 4B. & $3110 \pm 60$ & Semillas \\
\hline Beta-181402 & Departamento XIX. 3 ${ }^{\text {a }}$ & $3110 \pm 60$ & Semillas \\
\hline Beta-181403 & Departamento XX. Poste. & $3350 \pm 70$ & Carbón \\
\hline Beta-181405 & Departamento XX. Nivel intermedio. & $3180 \pm 70$ & Cereal \\
\hline Beta-181404 & Departamento XX. Nivel de incendio I. & $3080 \pm 60$ & Carbón \\
\hline Beta-195928 & Departamento XXV. Enterramiento. & $3410 \pm 50$ & Hueso humano \\
\hline Beta-195929 & Departamento XXV. Relleno bajo pavimento. & $3350 \pm 60$ & Carbón \\
\hline Beta-195924 & Departamento XXV. Sobre pavimento. & $3270 \pm 40$ & Cereal \\
\hline Beta-195925 & Departamento XXV. Junto peine marfil. & $3250 \pm 40$ & Carbón \\
\hline Beta-195926 & Departamento XXV. Cubeta superior. & $3090 \pm 70$ & Carbón \\
\hline Beta-189003 & Interior vástago punta bronce. & $3310 \pm 40$ & Carbón \\
\hline Beta-277068 & Departamento XXVII. Construcción de último pavimento. & $3240 \pm 40$ & Hordeum vulgare L. \\
\hline Beta-277069 & Departamento XXVII. Nivel incendio 3 ${ }^{\text {a fase. }}$ & $3310 \pm 40$ & Hordeum vulgare L. \\
\hline GRN-5109 & Departamento XV. Estrato IV. & $3300 \pm 55$ & Carbón \\
\hline Beta-189004 & Relleno exterior rampa acceso. Enterramiento. & $3280 \pm 70$ & Hueso humano \\
\hline H-2277 & Departamento VII. Estrato IV. & $3550 \pm 55$ & Carbón \\
\hline Beta-292033 & Departamento XXX. Incendio único nivel ocupación. & $3310 \pm 40$ & Hordeum vulgare L. \\
\hline Beta-277067 & Espacio abierto. Estructura aislada. & $3260 \pm 40$ & Triticum aestivum durum \\
\hline Beta-195927 & Departamento XXI. Uso del pavimento. & $3140 \pm 60$ & Carbón \\
\hline
\end{tabular}

Fig. 8. Relación de las dataciones de Cabezo Redondo, con indicación de su información contextual.

Por último, la serie de Cabezo Redondo (Hernández 2009b) se compone de 20 dataciones (fig. 8). Entre ellas se incluyen las fechas H-2277 y GrN-5109, que fueron las primeras obtenidas en el yacimiento por J. M. Soler García (1987). La primera de ellas, proveniente de la madera de un poste para la sujeción de la techumbre del Departamento VI, continúa siendo en la actualidad la más elevada de la serie. De las obtenidas en las excavaciones más recientes, la más antigua corresponde también a un poste de madera, en este caso del Departamento XIX Beta-181406. Las restantes se sitúan entre 1870/1600 cal BC y 1450/1190 cal BC. La primera de éstas, conjuntamente con otra -1770/1485 cal BC (Beta-189004)-, obtenidas ambas sobre hueso, corresponden a distintos puntos del relleno antrópico que colmata las zonas bajas para nivelar el brusco descenso de la roca y sobre el que se levantan varias construcciones. Una de ellas es una rampa que comunica dos terrazas, sobre la que se colocaron cuatro puntas de lanza con enmangue tubular. La madera de una de ellas -Beta-189003- ha proporcionado una fecha entre 1700/1520 cal BC. Otras dataciones, tomadas de pequeños carbones y cereales del mismo nivel de ocupación, han permitido fijar con cierta aproximación la cronología de algunas de las remodelaciones arquitectónicas y urbanísticas que se advierten en la estratigrafía del yacimiento. Además de esto, se ha señalado la asociación contextual de varias de las fechas con algunos objetos singulares (Hernández 2009b). Así, la fecha Beta-181405 se asocia a una cerámica decorada con mamelones en toda su superficie externa; la fecha Beta-195924 con una copa de pie bajo y un recipiente tipo Cogotas I con una banda horizontal paralela al borde y guirnaldas colgantes realizadas con la técnica de boquique, y por último, un excepcional peine (Hernández 2003) fue localizado en el interior de una cubeta en el extremo de un banco junto a varios carbones, uno de los cuales proporcionó la fecha Beta-195925.

En total cerca de 90 dataciones absolutas para un territorio relativamente reducido, procedente de una docena de yacimientos entre los que se cuentan tanto emplazamientos argáricos como del Grupo del Prebético meridional valenciano. De entre ellos destacan claramente por su importancia, superficie excavada, información estratigráfica, registro artefactual y serie radiocarbónica los yacimientos de Terlinques, Cabezo Pardo y Cabezo Redondo. Esta información de mejor calidad es la que constituye la base del modelo probabilístico desarrollado. 


\section{CALIBRACIÓN BAYESIANA, INFERENCIA ESTA- DÍSTICA Y MODELO PROBABILÍSTICO BÁSICO EN LAS DATACIONES RADIOCARBÓNICAS}

La calibración de las dataciones radiocarbónicas bajo los principios de la estadística bayesiana supone para la arqueología una revalorización de la estratigrafía como herramienta de información cronológica para la interpretación histórica. Hace unos años, Alex Bayliss (2009: 134) señalaba que más del 70\% de los 3000 análisis de radiocarbono realizados por el English Heritage entre 1993 y 2007 se habían tratado mediante la estadística bayesiana, lo que permite ponderar la distancia que en este campo nos separa con respecto al ámbito anglosajón. Aunque en nuestro país algunos de los primeros ensayos se remontan a principios de siglo -y no precisamente aplicados al campo de la Prehistoria (Rubinós 1999; Alonso et al. 2004)- la implantación de esta metodología en la investigación del Calcolítico y la Edad del Bronce en la península Ibérica está prácticamente iniciándose (Mataloto y Boaventura 2012; Boaventura y Mataloto 2013; Scarre 2010; Lull et al. 2010; 2013a; 2013b; Aranda y Lozano 2014), pero no cabe duda de que contribuirá a corto plazo a mejorar las estimaciones de índole cronológica hasta ahora aplicadas a los procesos históricos que constituyen nuestro objeto de estudio.

Se debe tener muy presente que el radiocarbono data objetos y no depósitos. La información tafonómica de los depósitos sedimentarios se constituye así en pieza primordial del método, pues sin una correcta determinación de la historia deposicional y ocupacional de cada contexto arqueológico no se puede abordar con garantías su datación. Ésta deberá siempre ser realizada a partir de muestras que por sus características se hallen directamente relacionadas con diversas actividades materializadas en los contextos arqueológicos -construcción, uso, mantenimiento, destrucción y abandono- y de las que interese establecer la cronología.

El objetivo de la incoporación de la estadística al diseño e interpretación de cronologías en estudios arqueológicos es similar al de cualquier otra disciplina en la que se utilicen datos empíricos (Williams 2012). Éste es el de aprender de magnitudes desconocidas basadas en estudios empíricos, gestionando formalmente la incertidumbre inherente a todo proceso de medición.
En nuestro contexto esto se traduce en que las dataciones radiocarbónicas -las observaciones, en adelante denotadas genéricamente como $x$ - se reconocen como mediciones imprecisas -y por tanto, sujetas a cierto error- de la fecha real de ocurrencia de determinados hechos históricos de interés cuyos valores son en general desconocidos. Siguiendo la tradición mayoritaria, denotaremos por letras griegas tales como $\theta, \alpha$ y $\beta$ a estas magnitudes desconocidas y que en terminología estadística genérica se les denomina parámetros. La estadística tiene como encargo el de inferir sobre estos parámetros desconocidos utilizando la información proporcionada por la muestra. Este proceso de aprendizaje se denomina inferencia estadística y normalmente viene en la forma de estimaciones puntuales -valores representativos de los parámetros- o por intervalos -par de valores entre los que esperamos que el parámetro se sitúe con determinada certidumbre.

El nexo clave que relaciona variables y parámetros son los modelos probabilísticos o modelos estadísticos. A grandes rasgos podemos entender que éstos son una modelización matemática -en términos de distribuciones de probabilidad- de la magnitud del error en las dataciones radiocarbónicas.

El modelo probabilístico básico que utilizaremos aquí es el usual (Buck 2003):

$x=\mu(\theta)+\varepsilon$,

donde $\theta$ representa la fecha calendárica-desconocidadel evento de interés en años de calendario BP -cal BP-; $x$ es la datación radiocarbónica obtenida en el laboratorio a partir de una muestra de materia orgánica asociada con el evento en cuestión; $\mu()$ es una función matemática que relaciona fechas calendáricas -en cal $\mathrm{BP}$ - con fechas radiocarbónicas BP. De esta forma $\mu(\theta)$ es la fecha radiocarbónica de un evento con fecha calendárica $\theta$. Esta función es desconocida, pero se aproxima por la curva de calibración internacional (Reimer et al. 2013). El componente probabilístico en la ecuación es el término que representa el error -intrínseco a cualquier proceso de medición- de laboratorio originado en la datación radiocarbónica y en la propia curva $\mu()$. Este término comúnmente se asume que es un error aleatorio con distribución normal -también llamada Gaussiana- de media cero y varianza $\sigma^{2}+\sigma_{u}^{2}$ que es la suma de la varianza proporcionada por el laboratorio -precisión en la datación- y la varianza de la curva $\mu()$. Esta suposición la abreviaremos como $\varepsilon \sim N\left(0, \sigma^{2}+\sigma_{\mu}^{2}\right)$. 


\section{LA APROXIMACIÓN BAYESIANA}

Todo lo dicho en el apartado anterior es común a los dos paradigmas de inferencia estadística predominantes: la aproximación clásica y la aproximación bayesiana. El modelo probabilístico asumido define la función de verosimilitud que es un componente común a ambos paradigmas. Sin embargo, la aproximación clásica considera a los parámetros desconocidos como valores fijos y constantes, y la escuela bayesiana, precisamente por ese desconocimiento, identifica a los parámetros como variables aleatorias y, por tanto, susceptibles de ser evaluadas con razonamientos probabilísticos (Gelman et al. 2004; Lee 2004). Por ejemplo, en la aproximación bayesiana una inferencia por intervalo -al 80\%- de una fecha calendárica de un evento que se pretende datar se interpreta como que la probabilidad de que el evento haya ocurrido en ese intervalo, basada en la información disponible, es del 80\%. Este tipo de afirmaciones están vetadas en la aproximación clásica y los resultados tienen una interpretación frequentista -en términos de qué ocurriría si el experimento de la datación ocurriera un gran número de veces.

Sin embargo, desde un punto de vista pragmático, no hay duda de que la característica fundamental que ha atraído en los últimos años la atención de los investigadores a la aproximación bayesiana, en este caso a la arqueología (Buck et al. 1996) es la posibilidad de incorporar fácilmente información a priori sobre los acontecimientos históricos que se analizan. La naturaleza de esta información puede ser muy variada, pero para el problema de la datación de información estratigráfica, la más común es la de ordenación de eventos. Si $x_{1}$ y $x_{2}$ son dos dataciones radiocarbónicas de eventos con fechas calendáricas $\theta_{1}$ y $\theta_{2}$ y $x_{1}$ es una observación correspondiente a un estrato más profundo, entonces la información a priori obtenida de la estratigrafía se traduce en que $\theta_{1}>\theta_{2}$.

Aparte de este tipo de información relativa, cualquier otro tipo de conocimiento -que sea independiente del proporcionado por las observaciones- se puede introducir en el procedimiento bayesiano. El resultado son inferencias más precisas y congruentes con toda la información disponible.

La información a priori y muestral se combinan, por medio del teorema de Bayes, en una distribución de probabilidad de los parámetros desconocidos (los $\theta$ 's, $\eta$ 's y $\beta$ 's) condicionada a la información de las dataciones radiocarbónicas -las $x$ 's - y la información a priori. Esta distribución es la conocida como distribución a posteriori de los parámetros y es la pieza básica para la obtención de cualquier tipo de inferencias en la aproximación bayesiana. El teorema de Bayes, aunque extremadamente potente en el mecanismo de aprendizaje estadístico, es simple. Sintéticamente se puede formular como:

a posteriori $=$ a priori $x$ modelo de las observaciones.

La distribución a posteriori -que es la expresión matemática correspondiente a la distribución de probabilidad de los parámetros desconocidos condicionada a las observaciones y la información a priori- se resume en gráficos, valores numéricos e intervalos que hacen más sencilla su interpretación por parte de los investigadores. En este trabajo, por ejemplo, veremos sintetizada la distribución a posteriori en representaciones gráficas -histogramas de la distribución a posteriori-; valores puntuales -modas o valores más probables- e intervalos de alta probabilidad -intervalos entre los que es muy probable que se encuentre el(los) parámetro(s) desconocido(s).

Usualmente, las matemáticas necesarias para analizar la distribución a posteriori son complejas. Esta circunstancia conlleva tener que evaluar esta función de forma indirecta, típicamente por medio de técnicas de simulación (Robert y Casella 2004). Existe en la actualidad software específico para abordar las tareas de simulación. En este trabajo utilizaremos el programa WinBUGS (Lunn et al. 2000) gestionado desde R (R Core Team 2013; Sturtz et al. 2005) que es, sin ninguna duda, uno de los programas más populares para resolver problemas aplicados bayesianos. Aunque de una interfaz un poco menos amistosa que otros programas específicos como BCal (Buck et al. 1999) u Oxcal (Bronk Ramsey 1994; 2009), WinBUGS es una herramienta enormemente flexible que directamente gestiona los modelos probabilísticos. Evidentemente, el uso del WinBUGS requiere un mínimo entrenamiento en técnicas estadísticas bayesianas, pero tiene la recompensa de que su uso es mucho más transparente. Por otro lado, el uso de este software en la datación radiocarbónica no es nuevo (Millard 2005).

UN MODELO PARA LA ESTIMACIÓN DE LAS CRONOLOGÍAS ATRIBUIDAS A LAS FASES ARQUEOLÓGICAS EN LOS YACIMIENTOS DE TERLINQUES, CABEZO PARDO Y CABEZO REDONDO

En este apartado seguiremos la convención de usar el superíndice $T$ para denotar dataciones radiocarbónicas, fechas calendáricas y parámetros en general del yacimiento de Terlinques. Además, como habitualmente se establece 
en estadística, los subíndices etiquetan las diferentes magnitudes. Por ejemplo $x_{3}^{\mathrm{T}}$ denota la tercera observación del yacimiento de Terlinques, que en virtud de la convención de la tabla de la figura 9 representa la datación con etiquetado de laboratorio Beta-189753. De forma semejante, usaremos el superíndice $P$ para Cabezo Pardo y $R$ para Cabezo Redondo.

Los modelos que hemos ajustado son muy similares para los tres yacimientos

Terlinques: $x_{i}^{T}=\mu\left(\theta_{j}^{T}\right)+\varepsilon_{i}, \quad \varepsilon_{i} \sim N\left(0, \sigma_{i}^{2}+\sigma_{\mu}^{2}\right), i=1,2, \ldots, 17$; $j=1,2, \ldots, 15$

Cabezo Pardo: $x_{i}^{P}=\mu\left(\theta_{j}^{P}\right)+\varepsilon_{i}, \varepsilon_{i} \sim N\left(0, \sigma_{i}^{2}+\sigma_{\mu}^{2}\right), i, j=1,2, \ldots, 16$ Cabezo Redondo: $x_{i}^{R}=\mu\left(\theta_{j}^{R}\right)+\varepsilon_{i}, \varepsilon_{i} \sim N\left(0, \sigma_{i}^{2}+\sigma_{\mu}^{2}\right)$, $i, j=1,2, \ldots, 19$

Ha sido necesario emplear diferentes subíndices $-i$ y $j$ - debido a que algunas observaciones están ligadas al mismo parámetro (puesto que son dataciones del mismo

\begin{tabular}{|c|c|c|c|c|c|}
\hline Matrícula & $\boldsymbol{x}$ & $\theta$ & $\begin{array}{c}\text { Datación } \\
\left(\boldsymbol{x}_{i} \pm \sigma_{i}\right)\end{array}$ & Fase & Contexto \\
\hline Beta-240938 & $\boldsymbol{x}_{1}^{T}$ & $\theta_{1}^{T}$ & $3770 \pm 40$ & 1 & Inicio \\
\hline Beta-189753 & $\boldsymbol{x}_{2}^{T}$ & $\theta_{2}^{T}$ & $3750 \pm 60$ & 1 & Inicio \\
\hline Beta-136171 & $\boldsymbol{x}_{3}^{T}$ & $\theta_{3}^{T}$ & $3630 \pm 60$ & 1 & Uso \\
\hline Beta-227373 & $\boldsymbol{x}_{4}^{T}$ & $\theta_{4}^{T}$ & $3680 \pm 40$ & 1 & Final \\
\hline Beta-122343 & $\boldsymbol{x}_{5}^{T}$ & $\theta_{5}^{T}$ & $3640 \pm 70$ & 1 & Final \\
\hline Beta-122344 & $\boldsymbol{x}_{6}^{T}$ & $\theta_{6}^{T}$ & $3530 \pm 60$ & 1 & Final \\
\hline Beta-268988 & $\boldsymbol{x}_{7}^{T}$ & $\theta_{7}^{T}$ & $3640 \pm 40$ & 1 & Final \\
\hline Beta-268989 & $\boldsymbol{x}_{8}^{T}$ & $\theta_{8}^{T}$ & $3710 \pm 40$ & 1 & Final \\
\hline Beta-268990 & $\boldsymbol{x}_{9}^{T}$ & $\theta_{9}^{T}$ & $3600 \pm 40$ & 1 & Final \\
\hline Beta-189756 & $\boldsymbol{x}_{10}^{T}$ & $\theta_{10}^{T}$ & $3590 \pm 40$ & 2 & Uso \\
\hline Beta-136172 & $\boldsymbol{x}_{11}^{T}$ & $\theta_{11}^{T}$ & $3500 \pm 70$ & 2 & Uso \\
\hline Beta-240937 & $\boldsymbol{x}_{12}^{T}$ & $\theta_{12}^{T}$ & $3530 \pm 40$ & 2 & Final \\
\hline Beta-189757 & $\boldsymbol{x}_{13}^{T}$ & $\theta_{13}^{T}$ & $3420 \pm 80$ & 2 & Final \\
\hline Beta-256351 & $\boldsymbol{x}_{14}^{T}$ & $\theta_{14}^{T}$ & $3450 \pm 40$ & 3 & Uso \\
\hline Beta-227575 & $\boldsymbol{x}_{15}^{T}$ & $\theta_{15}^{T}$ & $3310 \pm 40$ & 3 & Uso \\
\hline Beta-190806 & $\boldsymbol{x}_{16}^{T}$ & $\theta_{16}^{T}$ & $3330 \pm 70$ & 3 & Uso \\
\hline Beta-189754 & $\boldsymbol{x}_{17}^{T}$ & $\theta_{17}^{T}$ & $3300 \pm 60$ & 3 & Final \\
\hline Beta-227574 & $\boldsymbol{x}_{18}^{T}$ & $\theta_{18}^{T}$ & $3380 \pm 40$ & 3 & Uso \\
\hline Beta-189758 & $\boldsymbol{x}_{19}^{T}$ & $\theta_{19}^{T}$ & $3210 \pm 100$ & 3 & Uso \\
\hline
\end{tabular}

Fig. 9. Tabla de dataciones de Terlinques. evento). La relación exacta entre dataciones y parámetros está recogida en las tablas de las figuras 9, 10 y 11 . La información a priori disponible para cada yacimiento es distinta y se ha incorporado en cada modelo de forma específica. En el caso de Cabezo Redondo (fig. 11) la contextualización de las fechas radiocarbónicas está ligada a información estratigráfica todavía inédita o en proceso de análisis, de manera que asumiremos tan sólo que las observaciones datan eventos que acotan el inicio y abandono del yacimiento. Esto se expresa matemáticamente

$\alpha^{R} \geq\left\{\theta_{1}^{R}, \theta_{2}^{R}, \theta_{3}^{R}, \ldots, \theta_{14}^{R}\right\} \geq \beta^{R}$,

donde $\alpha^{R}$ y $\beta^{R}$ representan las fechas de inicio y final del yacimiento.

En Terlinques (fig. 9) y Cabezo Pardo (fig. 10) la información contextual posibilita una asignación precisa de la información a priori, lo que permite clasificar las dataciones según informan directamente del inicio, del momento de uso o de la destrucción o abandono de las unidades habitacionales y estructuras ligadas a cada fase arqueológica. Esta información sobre los $\theta$ 's la asignamos en el modelo para Terlinques como sigue:

- si $x_{i}^{T}$ es de uso de la fase $k(=1,2,3)$ de Terlinques: $\alpha_{k}^{T} \geq \theta_{j}^{T} \geq \beta_{k}^{T}$,

- si $x_{i}^{T}$ es de inicio de la fase $\mathrm{k}$ : $\alpha_{k}^{T}-r_{F} / 2 \leq \theta_{j}^{T} \leq \alpha_{k}^{T}+r_{F} / 2$ - si $x_{i}^{T}$ es de final de la fase $\mathrm{k}$ : $\beta_{k}^{T}-r_{D} / 2 \leq \theta_{j}^{T} \leq \beta_{k}^{T}+r_{D} / 2$.

Aquí $\alpha_{k}^{T}$ y $\beta_{k}^{T}$ son, respectivamente, las fechas de inicio de cada fase $k$ de Terlinques. La interpretación de los anteriores puntos es la siguiente. Las observaciones contextualizadas como de uso de una fase simplemente acotan los inicios y finales de la fase correspondiente. Cuando una datación $x_{i}^{T}$ ha sido contextualizada como de inicio de fase entonces informa de una fecha real, $\theta_{j}^{T}$, que data un evento que se produjo en el periodo de fundación de la fase, es decir en el intervalo centrado en $\alpha_{k}^{T}\left[\alpha_{k}^{T}-r_{F} / 2, \alpha_{k}^{T}+r_{F} / 2\right]$. De esta forma, el parámetro $r_{F}$ representa la duración de los procesos de fundación de las fases. Hemos asignado sobre $r_{F}$ una distribución $a$ priori uniforme entre 0 años y un máximo de 40 años reconociendo que, aún existiendo poca información sobre este parámetro, el proceso total de fundación no puede durar más de 40 años. Hemos utilizado otras posibilidades para este valor máximo (en concreto 100 años y 20 años) para concluir que los resultados son muy robustos 
RAdiocarbono y estadística bayesiana: APORTACIONES A la CRONOLOGía de LA EDAD DEL BRONCE EN EL EXTREMO ORIENTAL DEL SUDESTE DE LA PENÍNSULA IBÉRICA

\begin{tabular}{|c|c|c|c|c|c|}
\hline Matrícula & $\boldsymbol{x}$ & $\theta$ & $\begin{array}{c}\text { Datación } \\
\left(\boldsymbol{x}_{i} \pm \sigma_{i}\right)\end{array}$ & Fase & Contexto \\
\hline Beta-308903 & $\boldsymbol{x}_{1}^{P}$ & $\theta_{1}^{P}$ & $3590 \pm 30$ & 1 & Inicio \\
\hline Beta-268981 & $\boldsymbol{x}_{2}^{P}$ & $\theta_{2}^{P}$ & $3920 \pm 40$ & 1 & Inicio \\
\hline Beta-287332 & $\boldsymbol{x}_{3}^{P}$ & $\theta_{3}^{P}$ & $3620 \pm 40$ & 1 & Inicio \\
\hline Beta-258468 & $\boldsymbol{x}_{4}^{P}$ & $\theta_{4}^{P}$ & $3530 \pm 40$ & 1 & Final \\
\hline Beta-268980 & $\boldsymbol{x}_{5}^{P}$ & $\theta_{5}^{P}$ & $3500 \pm 40$ & 1 & Final \\
\hline Beta-268982 & $\boldsymbol{x}_{6}^{P}$ & $\theta_{6}^{P}$ & $3490 \pm 40$ & 1 & Final \\
\hline Beta-237765 & $\boldsymbol{x}_{7}^{P}$ & $\theta_{7}^{P}$ & $3460 \pm 40$ & 2 & Uso \\
\hline Beta-237766 & $\boldsymbol{x}_{8}^{P}$ & $\theta_{8}^{P}$ & $3390 \pm 40$ & 2 & Uso \\
\hline Beta-258466 & $\boldsymbol{x}_{9}^{P}$ & $\theta_{9}^{P}$ & $3440 \pm 40$ & 2 & Uso \\
\hline Beta-308902 & $\boldsymbol{x}_{10}^{P}$ & $\theta_{10}^{P}$ & $3450 \pm 30$ & 2 & Uso \\
\hline Beta-308904 & $\boldsymbol{x}_{11}^{P}$ & $\theta_{11}^{P}$ & $3460 \pm 30$ & 2 & Uso \\
\hline Beta-327334 & $\boldsymbol{x}_{12}^{P}$ & $\theta_{12}^{P}$ & $3350 \pm 40$ & 2 & Uso \\
\hline Beta-327335 & $\boldsymbol{x}_{13}^{P}$ & $\theta_{13}^{P}$ & $3450 \pm 30$ & 2 & Uso \\
\hline Beta-292077 & $\boldsymbol{x}_{14}^{P}$ & $\theta_{14}^{P}$ & $3350 \pm 40$ & 3 & Uso \\
\hline Beta-287333 & $\boldsymbol{x}_{15}^{P}$ & $\theta_{15}^{P}$ & $3330 \pm 40$ & 3 & Uso \\
\hline Beta-258467 & $\boldsymbol{x}_{16}^{P}$ & $\theta_{16}^{P}$ & $3300 \pm 40$ & 3 & Final \\
\hline
\end{tabular}

Fig. 10. Tabla de dataciones de Cabezo Pardo.

respecto a este parámetro. Las dataciones contextualizadas para el final de fase tienen una interpretación similar, aunque en este caso hemos fijado el valor máximo del proceso de destrucción de fase en 20 años.

Hemos seguido la misma estrategia en la especificación de la distribución a priori para los $\theta$ 's de Terlinques.

Los parámetros $\eta$ 's y $\beta$ 's representan respectivamente el inicio y el final de cada fase y extraer inferencias de estos parámetros es un objetivo fundamental de este estudio. Completamos la asignación de la distribución a priori asumiendo que todos los parámetros tienen una distribución de probabilidad uniforme en el intervalo $(0,5000)$ restringida a las desigualdades naturales de orden entre las fases:

$\alpha_{1}^{P} \geq \beta_{1}^{P} \geq \alpha_{2}^{P} \geq \beta_{2}^{P} \geq \alpha_{3}^{P} \geq \beta_{3}^{P}$

que equivale a decir que no tenemos información aparte de la relativa, expuesta arriba- sobre los parámetros desconocidos.

En particular, resulta de especial relevancia la comparación entre los inicios y finales de las fases entre los distintos yacimientos. Por ejemplo, la diferencia $\beta_{3}^{P}-\beta_{3}^{T}$ expresaría un valor temporal relativo entre los abandonos de Cabezo Pardo y Terlinques.

\begin{tabular}{|c|c|c|c|}
\hline Matrícula & $\boldsymbol{x}$ & $\theta$ & Datación $\left(\boldsymbol{x}_{i} \pm \sigma_{i}\right)$ \\
\hline Beta-181406 & $\boldsymbol{x}_{1}^{R}$ & $\theta_{1}^{R}$ & $3420 \pm 60$ \\
\hline Beta-181401 & $\boldsymbol{x}_{2}^{R}$ & $\theta_{2}^{R}$ & $3110 \pm 60$ \\
\hline Beta-181402 & $\boldsymbol{x}_{3}^{R}$ & $\theta_{2}^{R}$ & $3110 \pm 60$ \\
\hline Beta-181403 & $\boldsymbol{x}_{4}^{R}$ & $\theta_{3}^{R}$ & $3350 \pm 70$ \\
\hline Beta-181405 & $\boldsymbol{x}_{5}^{R}$ & $\theta_{4}^{R}$ & $3180 \pm 70$ \\
\hline Beta-181404 & $\boldsymbol{x}_{6}^{R}$ & $\theta_{4}^{R}$ & $3080 \pm 60$ \\
\hline Beta-195928 & $\boldsymbol{x}_{7}^{R}$ & $\theta_{5}^{R}$ & $3410 \pm 50$ \\
\hline Beta-195929 & $\boldsymbol{x}_{8}^{R}$ & $\theta_{6}^{R}$ & $3350 \pm 60$ \\
\hline Beta-195924 & $\boldsymbol{x}_{9}^{R}$ & $\theta_{7}^{R}$ & $3270 \pm 40$ \\
\hline Beta-195925 & $\boldsymbol{x}_{10}^{R}$ & $\theta_{8}^{R}$ & $3250 \pm 40$ \\
\hline Beta-195926 & $\boldsymbol{x}_{11}^{R}$ & $\theta_{9}^{R}$ & $3090 \pm 70$ \\
\hline Beta-189003 & $\boldsymbol{x}_{12}^{R}$ & $\theta_{10}^{R}$ & $3310 \pm 40$ \\
\hline Beta-277068 & $\boldsymbol{x}_{13}^{R}$ & $\theta_{11}^{R}$ & $3240 \pm 40$ \\
\hline Beta-277069 & $\boldsymbol{x}_{14}^{R}$ & $\theta_{12}^{R}$ & $3310 \pm 40$ \\
\hline GRN-5109 & $\boldsymbol{x}_{15}^{R}$ & $\theta_{13}^{R}$ & $3300 \pm 55$ \\
\hline Beta-189004 & $\boldsymbol{x}_{16}^{R}$ & $\theta_{14}^{R}$ & $3280 \pm 70$ \\
\hline H-2277 & $\boldsymbol{x}_{17}^{R}$ & $\theta_{15}^{R}$ & $3550 \pm 55$ \\
\hline Beta-292033 & $\boldsymbol{x}_{18}^{R}$ & $\theta_{16}^{R}$ & $3310 \pm 40$ \\
\hline Beta-277067 & $\boldsymbol{x}_{19}^{R}$ & $\theta_{17}^{R}$ & $3260 \pm 40$ \\
\hline Beta-195927 & $\boldsymbol{x}_{20}^{R}$ & $\theta_{18}^{R}$ & $3140 \pm 60$ \\
\hline
\end{tabular}

Fig. 11. Tabla de dataciones de Cabezo Redondo.

\section{RESULTADOS DEL AJUSTE DEL MODELO}

En los gráficos de la figura 12 se muestran las distribuciones a posteriori de los parámetros que definen los inicios ( $\alpha$ 's) y finales ( $\beta$ 's) de cada fase en cada uno de los dos yacimientos ${ }^{8}$. De acuerdo con los datos del modelo, los valores cronológicos que pueden proponerse para los inicios y finales de las fases arqueológicas reconocidas son los siguientes, expresados en forma de intervalos al $80 \%$ de probabilidad -[...]- en los que se incluye el valor más probable o moda. En algunos casos, la distribución es multimodal, por lo que se adjuntan todas ellas ordenadas de mayor a menor importancia.

\section{Terlinques:}

Fase I: $\alpha_{1}^{T} 2151$ [2129, 2280] - $\beta_{1}^{T}$ 1986, 2015 [1978, 2031] cal BC

Fase II: $\alpha_{2}^{T} 1946$ [1890, 1999] - $\beta_{2}^{T} 1741,1861,1801$ $[1731,1861]$ cal BC

Fase III: $\alpha_{3}^{T} 1741[1660,1779]-\beta_{3}^{T} 1511[1444,1612]$ cal BC 


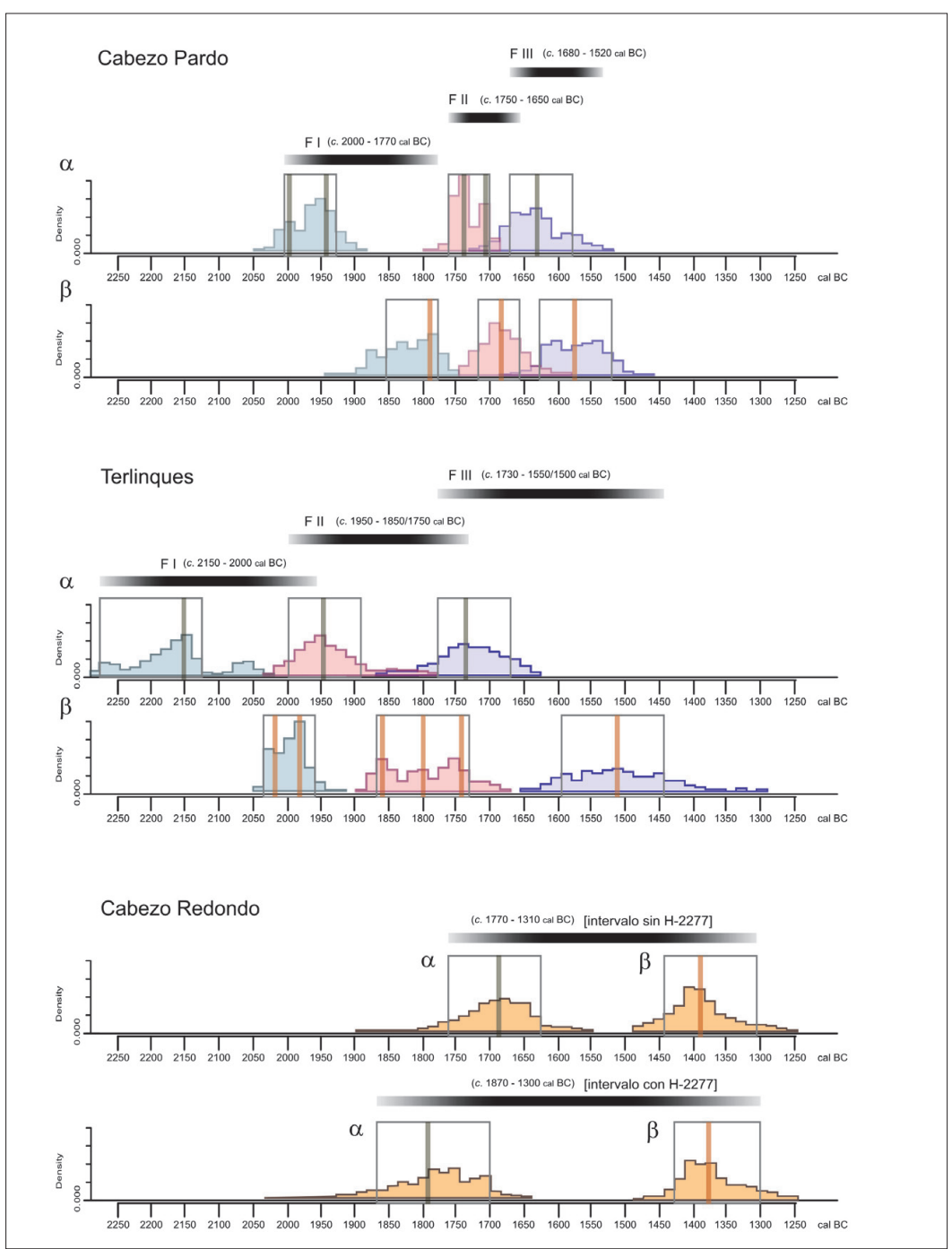

Fig. 12. Distribuciones a posteriori de los parámetros $\alpha$ 's y $\beta$ 's para cada fase de los yacimientos estudiados.

Cabezo Pardo:

Fase I: $\alpha_{1}^{P}$ 1936, $1996[1926,2006]-\beta_{1}^{P} 1790[1768$, 1864] cal BC

Fase II: $\alpha_{2}^{P} 1741,1706[1706,1754]-\beta_{2}^{P} 1671[1655$, 1732] cal BC

Fase III: $\alpha_{3}^{P} 1631[1584,1684]-\beta_{3}^{P} 1566[1525,1619]$ cal BC

\section{Cabezo Redondo:}

Sin H-2277: $\alpha^{R} 1691[1628,1744]-\beta^{R} 1391[1345,1458]$ cal BC

Con H-2277: $\alpha^{R} 1756$ [1706, 1850] $-\beta^{R} 1381[1318,1432]$ cal BC
La conclusión más relevante es que los resultados del ajuste del modelo evidencian en varios casos una elevada sincronía entre los procesos de construcción y destrucción de las estructuras y edificios asociados a varias de las fases arqueológicas reconocidas en los yacimientos. Esto se puede apreciar aún más claramente en la figura 13 , en la que hemos representado las estimaciones puntuales del modelo (modas a posteriori) de los distintos $\alpha$ 's y $\beta$ 's.

En síntesis, estos resultados sugieren las siguientes hipótesis en relación al orden cronológico más verosímil de las distintas fases registradas arqueológicamente:

a) La fundación de Terlinques $\left(\alpha_{1}^{T}\right)$ es muy anterior a la fundación de Cabezo Pardo $\left(\alpha_{l}^{P}\right)$; 


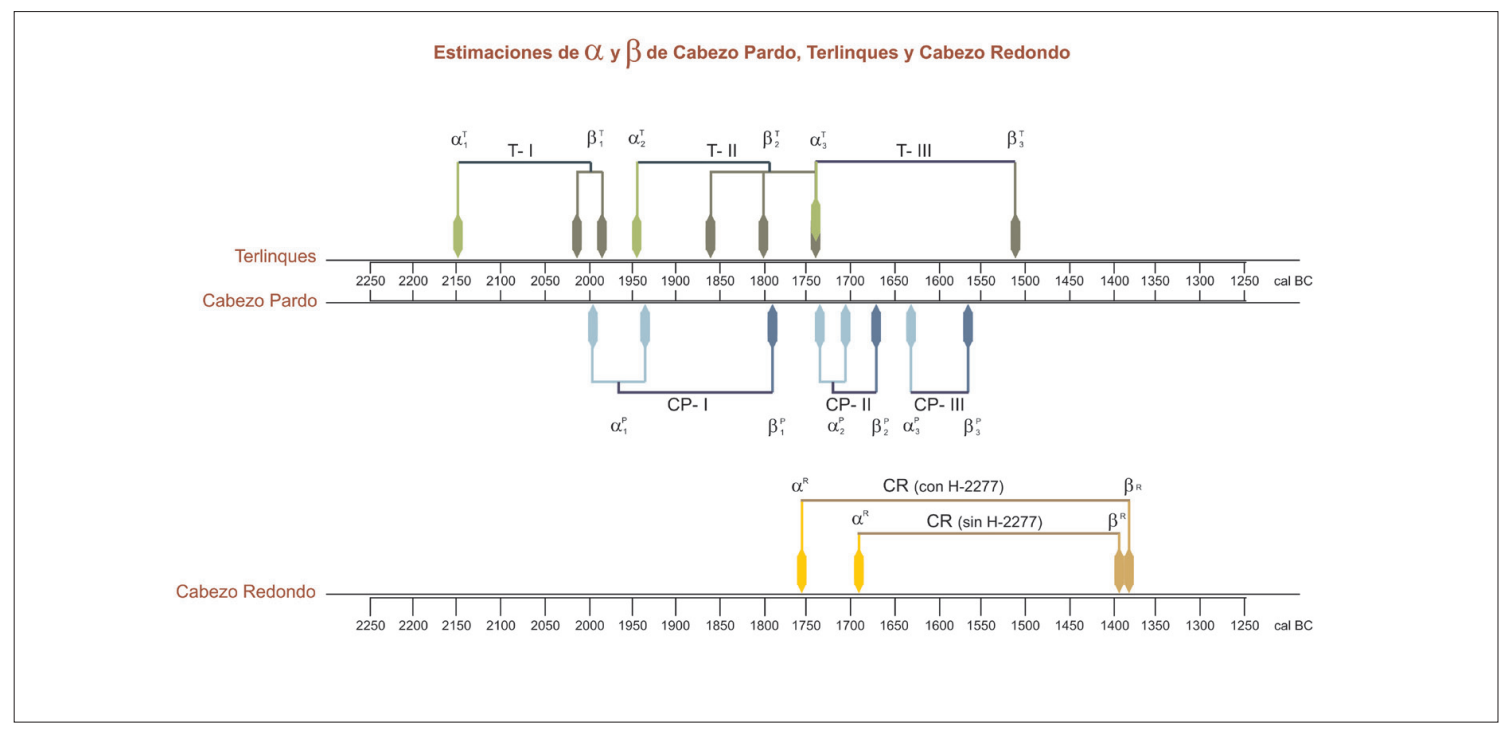

Fig. 13. Distribución de estimaciones puntuales -modas a posteriori- de los parámetros $\alpha$ 's y $\beta$ 's de cada fase para cada uno de los yacimientos estudiados.

b) El periodo de transición entre fase I y fase II de Terlinques $\left(\beta_{1}^{T}\right.$ y $\left.\alpha_{2}^{T}\right)$ es concordante con la fundación de Cabezo Pardo $\left(\alpha_{1}^{P}\right)$;

c) El final de la segunda fase de Terlinques $\left(\beta_{2}^{T}\right)$ es coincidente o ligeramente posterior al final de la primera fase de Cabezo Pardo $\left(\beta_{l}^{P}\right)$;

d) El inicio de la fase II de Cabezo Pardo $\left(\alpha_{2}^{P}\right)$ está en sincronía con el de la Fase III de Terlinques $\left(\alpha_{3}^{T}\right)$. Los procesos de destrucción documentados en el final de la fase II y de reconstrucción de la fase III en Cabezo Pardo $\left(\beta_{2}^{P}\right.$ y $\left.\alpha_{3}^{P}\right)$ son anteriores al final de la fase III de Terlinques $\left(\beta_{3}^{T}\right)$, que es contemporánea o ligeramente posterior al final de la fase III de Cabezo Pardo $\left(\beta_{3}^{P}\right)$.

e) El abandono de Terlinques $\left(\beta_{3}^{T}\right)$ y de Cabezo Pardo $\left(\beta_{l}^{P}\right)$ es anterior al abandono de Cabezo Redondo $\left(\beta^{R}\right)$.

Las hipótesis anteriores tienen asociada una incertidumbre que se puede apreciar en las figuras 14 y 15 en las que hemos representado las distribuciones a posteriori (en forma de histogramas) de las diferencias entre $\alpha$ 's y $\beta$ 's involucrados en el escenario descrito. La aproximación bayesiana permite cuantificar estas diferencias y evaluar las hipótesis en términos probabilísticos:

1. Respecto a la hipótesis a), encontramos que la media de $\alpha_{1}^{T}-\alpha_{1}^{P}$ es 203 años con un intervalo de probabilidad al $80 \%$ de $(130,304)$. Podemos establecer que la primera ocupación de Terlinques ocurrió muy posiblemente (una probabilidad aproximada de 0,80 ) en el intervalo 2280-2129 cal BC, con fecha más probable (moda a posteriori) $2151 \mathrm{cal}$ BC. Esto se aviene a las fechas que marcan el inicio de la Edad del Bronce en gran parte del mediodía peninsular, en torno a $2200 \mathrm{cal}$ BC (Lull et al. 2010). Esta datación, por otra parte, se muestra coherente con las escasas dataciones disponibles en el entorno más inmediato del territorio en estudio para contextos de la fase arqueológica precedente-Arenal de la Costa y casco urbano de Lorca- así como también con las dataciones de la última fase de ocupación del yacimiento de La Vital (Pérez et al. 2011) (ver fig. 2).

2. De igual forma, en b) la media de $\beta_{1}^{T}$ - $\alpha_{l}^{P}$ es 34 años con intervalo $(-15,80)$ y la media de $\alpha_{1}^{P}-\alpha_{2}^{T}$ es 26 años con intervalo de $80 \%$ de probabilidad $(-57,83)$. De acuerdo con los datos, el comienzo de la ocupación de Cabezo Pardo en su fase I $\left(\alpha_{1}^{P}\right)$ se produjo entre aproximadamente 2006 y 1926 cal BC (con probabilidad 0,80 ) y con 1996 o 1936 cal BC como fecha más probable, más bien hacia el final de la primera fase de ocupación de Terlinques $\left(\alpha_{2}^{T}\right)$ que se sitúa con probabilidad cercana al 0,80 en el intervalo 1999-1890 cal BC. Como hemos visto, existe una probabilidad alta de que la distancia temporal entre el inicio de la fase II de Terlinques y el comienzo de la fase I de Cabezo Pardo sea de unas pocas décadas. En consecuencia, las mayores probabilidades se dan en los casos de que el final de Terlinques I y el inicio de Cabezo Pardo I coincidieran o que éste último precediera ligeramente al primero. Sin duda se trata de un detalle de no poca trascendencia, pero que a la luz de los datos y de las 


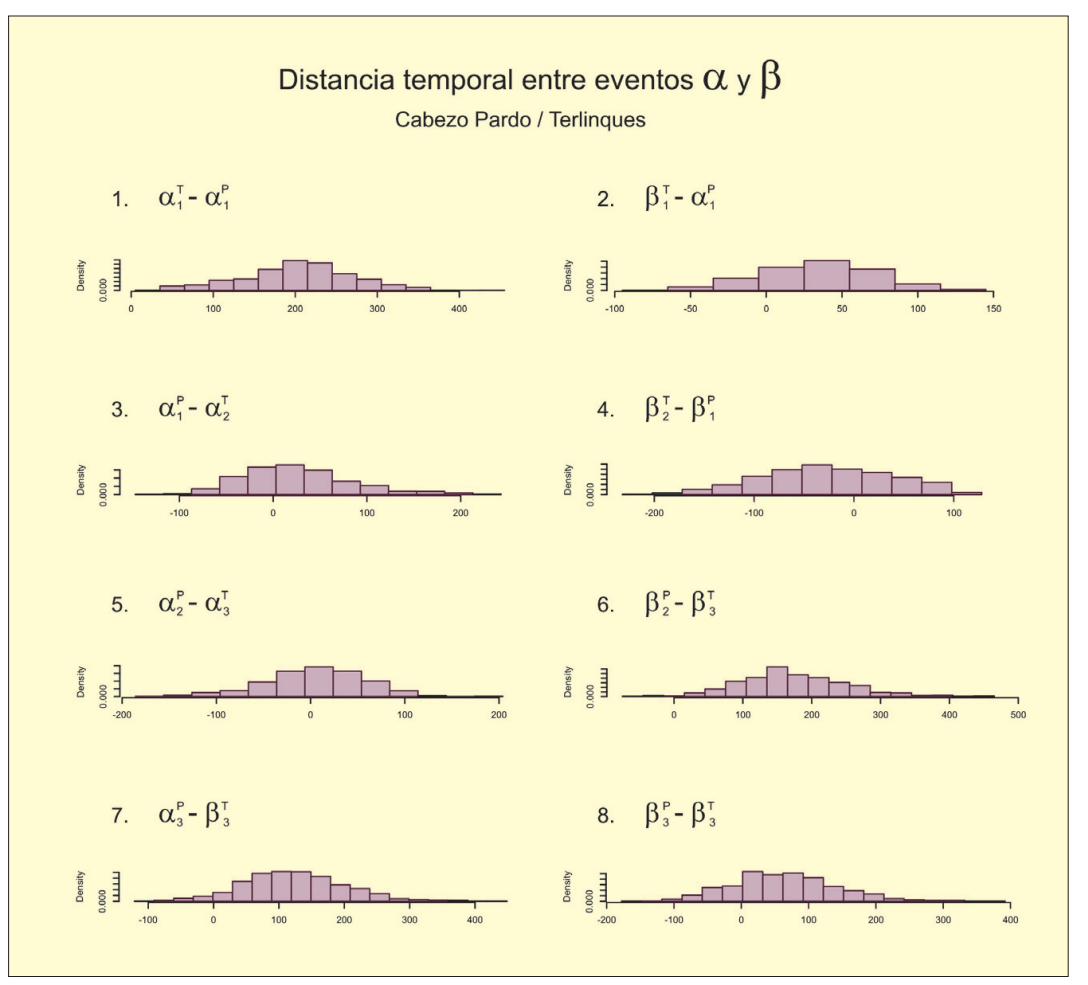

Fig. 14. Distribuciones a posteriori de las diferencias cronológicas estimadas entre las $\alpha$ 's y $\beta$ 's de las fases arqueológicas de Terlinques y Cabezo Pardo.

dataciones disponibles en la actualidad no puede aún dilucidarse. Por el momento, habremos de conformarnos con poner claramente de manifiesto la elevada sintonía de ambos eventos en lo cronológico.

3. En la cuantificación de c), la sincronía entre $\beta_{1}^{P}-\beta_{2}^{T}$ se evidencia con claridad en que la probabilidad de que la distancia temporal entre ambos fuera de menos de 50 años es de 0,50 llegando a una probabilidad de 0,86 para una distancia menor de 100 años. De hecho, como se muestra en la figura 14, la media de la distancia temporal estimada para $\left(\beta_{2}^{T}\right)-\left(\beta_{1}^{P}\right)$ es de 25 años con intervalo $(-94,80)$-o sea, de apenas una generación-y todavía más estrecha parece la distancia media de $\alpha_{2}^{P}$ y $\alpha_{3}^{T}$, de apenas 5 años con intervalo $(-54,74)$. Esta coincidencia en el tiempo resulta tanto más relevante por cuanto que también coincide, en uno y otro emplazamiento, con la implantación de un modelo urbanístico muy similar: una calle transversal a lo largo de la cima del cerro que articula en torno suyo un conjunto de unidades habitacionales de tamaño más o menos modular y en las que se advierten diferencias en cuanto al tipo de actividades llevadas a cabo en su interior.

4. Respecto a d) encontramos que la diferencia entre $\beta_{l}^{P}$ y $\beta_{3}^{T}$ es positiva con una probabilidad de 0.99 y de forma semejante la probabilidad de que $\alpha_{3}^{P}$ sea mayor que $\beta_{3}^{T}$ es muy alta (0.95). La diferencia entre $\beta_{3}^{P}$ y $\beta_{3}^{T}$ no es tan contundente y no descarta la sincronía entre ambos eventos con una diferencia media de 64 años y un intervalo de probabilidad de 0.80 de $(-49,147)$.

5. La transición entre el final de Cabezo Pardo II $\left(\beta_{2}^{P}\right)$ e inicio de Cabezo Pardo III ( $\left.\alpha_{3}^{P}\right)$ se sitúa (probabilidad $0,80)$, entre 1699 y 1626 cal BC, sin que este evento encuentre reflejo alguno en la secuencia radiocarbónica de Terlinques, cuya fase III concluye muy probablemente (probabilidad de 0,90 ) con posterioridad a $1600 \mathrm{cal} \mathrm{BC}$. Por consiguiente, o bien supuso un acontecimiento de carácter puntual que afectó exclusivamente a este poblado, o bien estuvo relacionado con acontecimientos con respecto a los que Terlinques permaneció esencialmente al margen.

6. En lo que se refiere a la ocupación de Cabezo Redondo, de acuerdo con la evaluación de la serie radiocarbónica hoy disponible, y excluyendo del conjunto del análisis la datación H-2277 (Soler García 1987), dado que se trata de una muestra de vida larga en la que habría que considerar el efecto old wood -madera vieja- (Schiffer 1986), la fundación del mismo vendría a situarse en el intervalo 1744-1628 cal BC. En ese caso, en relación a 
Fig. 15. Distribuciones a posteriori de las diferencias cronológicas estimadas entre el inicio de Cabezo Redondo y $\alpha$ 's y $\beta$ 's de las fases II y III de Terlinques y Cabezo Pardo.

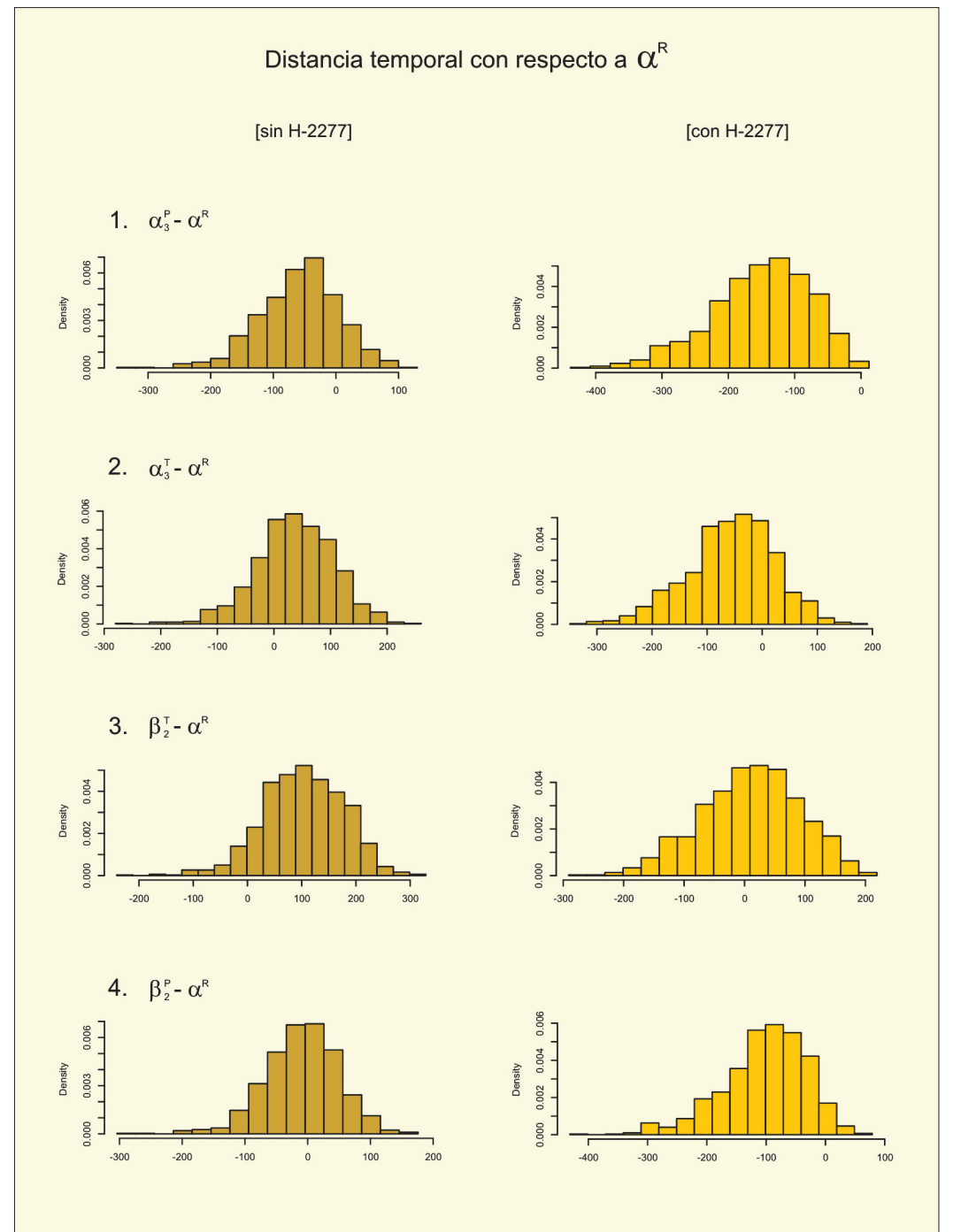

Cabezo Pardo los resultados son bastante concluyentes al respecto de que $\alpha^{R}$ sería en ese caso más antigua que $\alpha_{3}^{P}$ (probabilidad 0.82) y más moderna que $\alpha_{2}^{P}$ (probabilidad 0.80 ) (fig. 15). Los datos apuntan más bien hacia una considerable sincronía entre la fundación de Cabezo Redondo y el final de Cabezo Pardo II $\left(\beta_{2}^{P}\right)$, puesto que la diferencia entre ambos eventos no parece superar los 75 años (probabilidad 0.81). Todo esto situaría el comienzo de Cabezo Redondo en algún momento de la fase II de Cabezo Pardo, posiblemente cercano al final de ésta. Con respecto a Terlinques, $\alpha^{R}$ se situaría antes que el final de Terlinques III ( $\beta_{3}^{T}$ ) (probabilidad 0.99), lo que hace muy plausible la coexistencia de ambos asentamientos.
Igualmente, está muy avalado por el modelo que $\alpha^{R}$ sería posterior al inicio de Terlinques II $\left(\alpha_{2}^{T}\right)$ (probabilidad $0.99)$ y a su final $\left(\beta_{2}^{T}\right)$ (probabilidad 0.92). Si a todo esto añadimos su razonable sincronía con el inicio de Terlinques III $\left(\alpha_{3}^{T}\right)$-la probabilidad de que transcurran menos de 75 años entre ambos eventos es de 0.64- podemos concluir que en este caso el inicio de Cabezo Redondo se situaría en algún momento del tránsito entre las fases II y III de Terlinques.

7. El análisis del modelo ajustado también sugiere una marcada sintonía en cuanto al intervalo en el que se fija el abandono de los poblados de Terlinques y Cabezo Pardo. Ambos parecen estar, muy probablemente, 
desocupados con posterioridad a $1420 \mathrm{cal} \mathrm{BC}$, aunque lo cierto es que el momento concreto en que se produce dicha desocupación no parece poder fijarse con mucha precisión por ahora. En el caso de Terlinques, dicho evento al parecer se dio, con la mayor probabilidad, entre 1612 y 1444 cal BC, mientras que en Cabezo Pardo éste parece situarse preferentemente en el intervalo 1619-1525 cal BC. Según el modelo ajustado, podemos estimar la probabilidad de que entre ambos abandonos transcurrieran menos de 100 años en 0,70 .

8. En cuanto a e), lo que por otra parte parece también bastante claro es que ninguno de estos abandonos coincide en el tiempo con el final de la ocupación de Cabezo Redondo $\left(\beta^{R}\right)$. El resultado mas clarificador a este respecto es que encontramos que la probabilidad de que el abandono de Terlinques o de Cabezo Pardo fuera anterior al abandono de Cabezo Redondo es muy alta: al menos 0,92, independientemente de si se incluye o no la datación H-2277. En términos absolutos, el abandono de Cabezo Redondo se estima, con probabilidad 0,80 en el intervalo 1458-1345 cal BC -sin H-2277-, de manera que puede en principio afirmarse que los datos respaldan una continuidad de este yacimiento villenense más allá de la desocupación de asentamientos del tipo Terlinques o Cabezo Pardo.

9. Resulta relevante, por último, comprobar cómo ninguno de los enterramientos de Cabezo Redondo fechados hasta ahora ofrece intervalos claramente posteriores a 1500 cal BC. Según este dato, la realización de inhumaciones en el interior de las unidades habitacionales de Cabezo Redondo sólo resultaría coincidente en el tiempo con el desarrollo de las últimas fases de ocupación de Terlinques y de Cabezo Pardo, desapareciendo esta práctica a partir del momento en que se dio el abandono de éstos últimos, es decir, en el tramo cronológico de 1450-1300 cal BC, en el que sólo Cabezo Redondo permaneció vigente.

\section{TIEMPOS ARQUEOLÓGICOS PARA LA CONS- TRUCCIÓN DEL PROCESO HISTÓRICO EN EL CONFÍN ORIENTAL DE EL ARGAR}

En el presente artículo se ha intentado mostrar cómo la aplicación de un modelo bayesiano a un cuantioso -aunque todavía limitado- conjunto de dataciones absolutas debidamente contextualizadas, procedentes de tres asentamientos próximos, ubicados a un lado y otro del extremo septentrional del espacio social argárico, ha permitido incrementar nuestras certezas sobre la dinámica temporal de lo que denominamos Edad del Bronce, determinando la cronología de diversos eventos o transformaciones registradas en distintos asentamientos de una misma área geográfica y evaluando su eventual sincronía.

Toda estratigrafía se compone de un mosaico ordenado y sucesivo de contextos, cada uno de los cuales concreta en lo material un momento determinado -un contextomomento (Bate 1998: 109)- de transformación acontecido (ya sea en un instante o en un prolongado espacio de tiempo) en un yacimiento arqueológico: una refacción de un pavimento, un abocamiento de desperdicios, el cerramiento de un acceso a un espacio, la clausura de un hogar o la colmatación de un silo. Sin embargo, no todos estos cambios perceptibles en el registro adquieren el mismo valor desde el punto de vista de su significación histórica.

Desde posicionamientos esencialmente estructuralistas, en el marco de la denominada eventful archaeology (Bolender 2010), se ha teorizado acerca de la plasmación en el espacio -i.e. en la materialidad susceptible de ser registrada con metodología arqueológica (Beck et al. 2007) - y en el tiempo (Bayliss et al. 2007; Whittle et al. 2007) de aquellos eventos relacionados con rupturas y rearticulaciones estructurales, en oposición a aquéllos vinculados simplemente con la reproducción de las estructuras ya existentes.

Desde nuestros posicionamientos, sin embargo, los cambios materializados en el registro arqueológico asociados a variaciones en la organización interna de asentamientos y de amplios espacios territoriales, no pueden considerarse meros desajustes de unos sistemas necesitados de reequilibrio constante entre gestión y recursos, sino indicadores de transformaciones en el marco de las relaciones sociales de los grupos humanos que ocuparon dichos lugares y territorios. La cronología que el modelo bayesiano aquí presentado viene a fijar para dichas transformaciones en nuestro ámbito de estudio, constituye un elemento esencial en la formalización de una hipótesis sobre el proceso histórico de aquellas poblaciones, en la que venimos trabajando desde hace años (Jover y López Padilla 2004; 2009b).

En este sentido, la necesidad de fijar con la mayor precisión el desarrollo temporal de los asentamientos excavados y de los procesos en estudio ya había sido una cuestión ampliamente abordada en la investigación en el levante de la península Ibérica (Tarradell 1963: 180; Bernabeu 1984; Hernández 1986; Jover 1999; López 
Padilla 2011), al igual que otros aspectos como la caracterización de los patrones de ocupación del espacio social y la distribución de los asentamientos en el territorio (Jover y López 1999; López Padilla 2009); los modelos de articulación urbanística y su transformación a lo largo de las secuencias estratigráficas (Jover y López 2004; 2009a); o el grado de especialización productiva de determinadas unidades habitacionales (Hernández et al. 2013) y de asentamientos, en función de su localización en el territorio (Jover y López 2005).

No obstante, profundizar en dichos aspectos seguía resultando superfluo sin un armazón cronológico suficientemente fiable en el que ir encajando en fechas calendáricas las transformaciones y eventos que se advertían en las estratigrafías documentadas, por más que éstas hicieran ya evidente su sucesión diacrónica. Dicho armazón debía permitir además, en cada caso, evaluar la existencia o no de correlación temporal entre tales eventos respecto a las secuencias del conjunto de yacimientos excavados.

Sólo en los últimos años se ha estado en condiciones de afrontar la consecución de este objetivo con ciertas garantías. Para ello ha sido necesario disponer de tres elementos imprescindibles: unas secuencias estratigráficas bien documentadas, provenientes de yacimientos significativos, en las que se reflejaran convenientemente los principales episodios acontecidos en ellos durante su ocupación; unas series de dataciones radiocarbónicas capaces de informar de los intervalos cronológicos probables en los que dichos episodios acontecieron; y por último, las herramientas apropiadas para afinar al máximo la precisión de estas dataciones, estrechando en lo posible el margen de dichos intervalos. El resultado de este trabajo se concreta en la determinación de una serie de momentos en los que concurrieron diversos cambios relevantes materializados en el registro arqueológico, a los que cabe atribuir una destacada significación en el marco del proceso histórico que nos interesa inferir.

Con independencia de que en el futuro puedan concretarse mucho más las franjas temporales en las que se produjeron dichas transformaciones, parece evidente que en el transcurso de lo que denominamos la Edad del Bronce, en las tierras del SE y E de la península Ibérica se dieron situaciones relevantes de reorganización social y de alteraciones en los patrones de ocupación y explotación de los espacios ocupados en torno a las siguientes fechas:

\section{0/2150 CAL BC}

Los estudios efectuados sobre el conjunto de dataciones disponibles de asentamientos excavados en el ámbito del SE para momentos calcolíticos y argáricos, muestran una desarticulación del grupo millarense hacia estas fechas y un reconocimiento de lo argárico a partir de las mismas (Lull et al. 2010), en clara sintonía con los grandes cambios que sincrónicamente se están produciendo en otras zonas del Mediterráneo y de Europa (Lull et al. 2011: 383-386).

Disponemos de suficientes argumentos para fijar también en torno a ese mismo horizonte cronológico la fundación de asentamientos como Terlinques, ubicado más allá del espacio argárico. Éste no es el único yacimiento de estas características que ha proporcionado dataciones en torno a este horizonte cronológico. Aunque algunas sean antiguas, presenten amplias desviaciones y se hayan obtenido a partir de muestras de escasa fiabilidad -como Serra Grossa (Llobregat 1971) - y otras arrastren serios problemas de contextualización -como Mas del Corral (Trelis 1992)- nuevas dataciones aún inéditas y tomadas de muestras más fiables continúan fijando este momento para el inicio de las secuencias de ocupación de algunos yacimientos, como en el caso del Cabezo de la Escoba ${ }^{9}$. Por tanto, parece evidente que la fundación de Terlinques no fue un hecho aislado y que tendríamos que considerar estas fechas para la implantación, políticamente dirigida, de una importante reorganización poblacional a escala regional en prácticamente todo el Prebético meridional valenciano, con una nueva distribución de los espacios productivos y de la ubicación y organización interna de los asentamientos. En este momento se estaría iniciando lo que consideramos la Edad del Bronce.

La distribución sobre el territorio de dichos asentamientos, casi equidistante, aboga por plantear la fragmentación y reparto del espacio productivo entre los diferentes linajes propietarios del mismo, y la creación de nuevos núcleos estables ubicados en lo alto de cerros y de elevaciones montañosas. Distribución dispersa aunque ordenada, pero, en general, en el entorno de tierras sin grandes rendimientos para la actividad agropecuaria, aunque rentable en términos de salvaguarda del producto almacenado y de control visual del espacio productivo (Jover y López 2009b).

Parece lógico suponer que buena parte del contingente poblacional desplazado a estos nuevos asentamientos proviniese de los núcleos campaniformes ubicados sobre 
las terrazas fluviales o, en general, en los fondos de valle, cuyo abandono se produciría al mismo tiempo que se crearían estos nuevos núcleos en altura y que, por tanto, dejarían de estar ocupados también en torno a las mismas fechas. En cambio, es factible pensar que la mayoría de los asentamientos campaniformes que ya estaban asentados en lugares elevados -Peñón de la Zorra o El Monastil, por ejemplo- pudieran continuar ocupados más tiempo, al menos durante los momentos iniciales de la transición entre el modelo de explotación del espacio social típico del final del Calcolítico y la nueva estrategia basada en la fragmentación, reparto y ampliación de los espacios en explotación que se impuso como único medio de garantizar el incremento en términos absolutos del plusproducto disponible para la totalidad social.

La relación entre la implantación del grupo argárico en el $\mathrm{S}$ de Alicante y la aparición de los primeros asentamientos del entonces denominado Bronce Valenciano en el Vinalopó y en el Camp d'Alacant -y, por ende, la dependencia histórica de este proceso con respecto al primero- se planteó hace ya mucho tiempo (Bernabeu 1984; Hernández 1986). Esta hipótesis se fundamentaba básicamente en las notables diferencias apreciables entre uno y otro grupo arqueológico, algunas de las cuales se ponen de manifiesto de forma muy clara como, por ejemplo, en la diferente magnitud de los asentamientos argáricos frente a los del Prebético meridional valenciano (López Padilla 2009; Jover y López 2009b). Mientras núcleos argáricos como San Antón o Laderas del Castillo superaron ampliamente las 1,5 Ha de extensión, los asentamientos de mayor tamaño en el área del Prebético meridional valenciano, similares a Terlinques, apenas sobrepasaron las $0,3 \mathrm{Ha}$. A ello se añade la mayor capacidad organizativa y de movilización de fuerza de trabajo mostrada por el grupo argárico en la planificación y ejecución de infraestructuras, como evidencia, sin ir mas lejos, la muralla de La Bastida, en Totana, construida en estos mismos momentos (Lull et al. 2014).

La existencia de una clara interrelación socioeconómica entre ambas sociedades se encuentra, por otra parte, reflejada en el registro arqueológico tanto de los yacimientos argáricos como en los del Prebético meridional valenciano. La convivencia por vecindad y el mantenimiento de intercambios por necesidad social de determinados recursos -cobre, plata, marfil, adornos, etc. (Jover y López, 2009b)- controlados por los grupos dominantes argáricos, permitió hace ya unos años plantear, a modo de hipótesis, que las relaciones establecidas entre ambas estarían determinadas por una explotación intersocial impuesta por El Argar -calificada por diversos autores como una sociedad de clases (Arteaga 2000; Lull et al. 2009)- a los grupos periféricos del área valenciana que, en apariencia, no lo eran (Jover 1999). En el marco de dicha hipótesis, esta relación de explotación habría sido una de las causas principales que habrían instigado el proceso de reorganización poblacional descrito para el ámbito del Prebético meridional valenciano (Jover y López 2004; 2009b).

\section{0-1950 CAL BC}

De acuerdo con el modelo, en el horizonte fijado en torno a este intervalo cronológico concurren claramente varios eventos de diversa índole:

- por una parte, se constata la fundación (comienzo de la fase I) del asentamiento argárico de Cabezo Pardo, enclave que por su tamaño, localización y características, se puede considerar un asentamiento de tamaño más bien pequeño en el conjunto del poblamiento argárico del Bajo Segura;

- en las mismas fechas se sitúa la destrucción de Terlinques (fin de la fase I) y su reconstrucción (inicio de la fase II), que se llevará a cabo siguiendo aproximadamente los mismos patrones de organización urbanística del asentamiento característicos de su fase anterior;

- del mismo modo, la única fecha radiocarbónica obtenida en la excavación del pequeño asentamiento encumbrado de Barranco Tuerto permite aventurar su fundación también en estos momentos (Jover y López Padilla 2005).

Para el conjunto del ámbito argárico, la franja cronológica situada en torno a $1950 \mathrm{cal}$ BC ha sido señalada por algunos investigadores como referente temporal para la concreción en el registro de una serie de cambios transcendentales en la configuración de su espacio social y en el desarrollo de procesos de intensificación productiva, incremento en el número de los enterramientos infantiles y la aparición y/o normalización de nuevos tipos de tumbas y ajuares, lo que ha permitido proponer que hacia 1950 cal BC ya se habría consolidado El Argar como una sociedad de clases (Lull et al. 2011: 387-388; 2013b: 284).

En el marco de este proceso general resulta factible proponer, a la vista de los datos disponibles actualmente, que la fundación de Cabezo Pardo estuviera relacionada con una estrategia del grupo argárico orientada a la plena ocupación agropecuaria de los territorios del Bajo Segura y Bajo Vinalopó, en la que quizá hubiera que situar también la creación de otros asentamientos argáricos de la 
zona y de algunos pequeños núcleos especializados en el control de las vías de comunicación, como la Loma de Hurchillo o Caramoro I (González y Ruiz 1995).

En cualquier caso, el modelo muestra, aunque de forma no concluyente, que la fundación de Cabezo Pardo pudo darse incluso antes de la destrucción de la fase I de Terlinques, por lo que no puede descartarse una relación causa-efecto entre los procesos en los que creemos se enmarcan ambos acontecimientos. En todo caso, parece difícil negar la manifiesta correlación temporal que se advierte entre el desarrollo de la fase I de Cabezo Pardo y el de la fase II de Terlinques.

Por otra parte, que el arranque de la fase II de Terlinques resulte aproximadamente coincidente en el tiempo con la fundación de Barranco Tuerto -un asentamiento de muy pequeñas dimensiones, con una ubicación que primó claramente el desempeño de labores de control visual del territorio (Jover y López 2005)- hace plausible interpretar el desarrollo de un proceso en dos direcciones complementarias entre sí:

a) si, como creemos, el momento fundacional de Barranco Tuerto puede extrapolarse al del resto de asentamientos de similares características constatados en la zona del Prébetico meridional -como el Peñón de la Moneda o Sierra del Collado I (Jover y López 1999) - ello implicaría una mayor cohesión territorial e intensificación en la apropiación y ocupación plena del territorio, semejante al que hemos señalado que se habría producido o estaría produciéndose en el ámbito argárico del Bajo Segura y Bajo Vinalopó y que, como aquél, se manifestaría en la creación de enclaves orientados al incremento del control y vigilancia del espacio grupal.

b) esta estrategia dejaría definitivamente vacíos de función a los antiguos enclaves en altura campaniformes del Prebético meridional, cuya localización respondía primordialmente a una estrategia de control del conjunto del espacio grupal (López Padilla 2006: 232). Ésta quedaba ahora obsoleta ante un espacio repartido entre asentamientos, para cuya vigilancia resultaba mucho más operativa la nueva red de pequeños núcleos especializados, como el documentado en Barranco Tuerto. En consecuencia, cabe suponer que la gran mayoría de los asentamientos en altura de origen y materialidad "campaniforme" que aún continuaran ocupados, debieron abandonarse hacia el $1950 \mathrm{cal} \mathrm{BC}$ o poco después.

Por último, el incremento demográfico sostenido por la intensificación en la explotación agropecuaria podría estar también tras la fundación de otro tipo de enclaves, igualmente de pequeño tamaño pero, a diferencia de los situados sobre puntos de primado control visual del territorio, ubicados en las proximidades de otros asentamientos mayores, con respecto a los cuales se les ha supuesto dependientes (Jover y López 1999). Sería el caso de varias decenas de poblados similares al de Polovar-emplazado a poco más de un kilómetro en línea recta de Terlinques y con una única fase de ocupación- y que ha proporcionado la única datación radiocarbónica (aún inédita) disponible para este tipo de asentamientos. Ésta viene a situar el momento de destrucción de una de las edificaciones $c a$. 1830 cal BC, coincidente con el intervalo fijado por el modelo para el final de la fase II de Terlinques.

\section{0-1750 CAL BC}

Aproximadamente en este intervalo se dieron, por un lado, la destrucción de la fase II del asentamiento no argárico de Terlinques y, por otro, el final del asentamiento argárico de Cabezo Pardo en su fase I. En ambos casos con violentos incendios y la destrucción y completo desmantelamiento de su planta urbanística. Según los datos del modelo, hay una probabilidad muy alta de que entre ambos eventos apenas hubiera 25 años de diferencia. Así mismo, se constata la reconstrucción de los dos asentamientos (inicio de las fases III de Terlinques y II de Cabezo Pardo, respectivamente) siguiendo una ordenación en la disposición de las unidades habitacionales y de los espacios de comunicación entre ellas sensiblemente similar en ambos, y en fechas que, según el modelo, bien podrían haber sido perfectamente sincrónicas -apenas cinco años de diferencia-.

Es posible que asistamos también ahora a la fundación del asentamiento de Cabezo Redondo (aunque, como ya hemos visto, el modelo avala igualmente una fundación más tardía, dependiendo de la inclusión o no de la fecha H-2277) coincidiendo con el tránsito entre las fases II y III de Cabezo Pardo. El surgimiento de Cabezo Redondo, de una importancia y tamaño no conocidos hasta entonces fuera del ámbito argárico, se explicaría como resultado de la asunción por parte de sus habitantes de un papel rector a escala macro-territorial en el ámbito de la concentración y redistribución de productos y materias primas. El evidente "argarismo" de parte del registro artefactual y sobre todo de algunas de sus prácticas funerarias -como el enterramiento individual en el interior de las viviendas o la inhumación de niños en tinajas de cerámica- habla en favor de una proyección hacia Cabezo 
Redondo de los grupos dominantes argáricos, que probablemente pretendieron así continuar manteniendo bajo su control las rutas de intercambio y extenderlo sobre las poblaciones explotadas emplazadas más allá de la inicial frontera argárica.

La dicotomía en la materialidad que ofrece el registro arqueológico documentado en Cabezo Redondo frente al registrado en los yacimientos contemporáneos de su entorno, como Terlinques (fase III), manifiestamente inferiores a aquél en cuanto a la calidad y variedad de los productos consumidos o incluso a las dimensiones y características de las propias viviendas, queda reforzada ante el hecho de la ausencia de enterramientos en éstos y la presencia de inhumaciones -en algún caso con ajuares que incluían adornos y joyas de oro- en el subsuelo de las construcciones de Cabezo Redondo.

\section{0-1500 CAL BC}

Este horizonte temporal fija de forma muy clara el abandono definitivo tanto de Terlinques como de Cabezo Pardo, y marca el inicio de significativos cambios en Cabezo Redondo.

Es sumamente relevante que el primero de ambos eventos se produzca en un momento en el que se constata el abandono de numerosos asentamientos (Lull et al. 2013: 286-287, Fig.3, Tabla 1) y/o una profunda reestructuración de otros, circunstancia que se detecta a una escala interregional -e incluso europea (Risch y Meller 2013)- lo que ha llevado a algunos autores a fijar aquí el colapso de El Argar como entidad social (Lull et al. 2013b).

Hacia 1500 cal BC, en la fase arqueológica denominada como Bronce tardío (Molina 1978) o Post-Argar (Castro et al. 1996; Lull et al. 2013), se consolidaría una nueva organización territorial del poblamiento en todo el ámbito regional, en relación con una situación social y política completamente transformada. Grandes centros argáricos como La Bastida de Totana pasaron a ser núcleos secundarios o incluso fueron definitivamente abandonados, frente a otros, como Cabezo Redondo, cuyo tamaño, magnitud de las edificaciones y, especialmente, la capacidad de los grupos dominantes residentes de atesorar joyas de diferentes materias primas -especialmente de oro-, permiten atribuirle una posición preeminente en la dirección política del proyecto social previamente comandado desde los grandes enclaves del sudeste (Hernández et al. 2013).
No obstante, el liderazgo político de tales centros no pudo prolongarse mucho en el tiempo. El conjunto de las dataciones de Cabezo Redondo no permite pensar en una ocupación del asentamiento más allá de 1300 cal BC, momento en el que parece producirse una nueva restructuración territorial, asociada a una importante desagregación poblacional. De hecho, en la zona de estudio no volvería a alcanzarse un grado similar de nuclearización de la población en un gran asentamiento hasta el siglo IX cal BC, momento en que arranca la ocupación del importante enclave de Penya Negra (González Prats 1983; 1990).

Francisco Javier Jover Maestre Depto. Prehistoria, Arqueología, $\mathrm{H}^{\mathrm{a}}$ Antigua, Filología Griega y Filología Latina Universidad de Alicante javier.jover@ua.es

Juan Antonio LóPez Padilla Museo Arqueológico Provincial de Alicante (MARQ) Diputación Provincial de Alicante japadi@diputacionalicante.es

Gonzalo García-Donato Layrón Depto. de Análisis Económico y Finanzas Universidad de Castilla-La Mancha gonzalo.garciadonato@uclm.es

\section{NOTAS}

1. Agradecemos a M. S. Hernández Pérez, V. Barciela González y G. García Atiénzar la información contextual y las dataciones absolutas obtenidas en sus excavaciones en Cabezo Redondo, algunas de ellas todavía inéditas. Este trabajo se enmarca en el desarrollo de los proyectos de excavaciones arqueológicas en "Terlinques" y "Cabezo Pardo", autorizadas por la Dirección General de Patrimonio de la Consellería de Educación, Cultura y Deportes de la Generalitat Valenciana

2. Las excavaciones que desde 2010 viene llevando a cabo G. García Atiénzar (Universidad de Alicante) en el yacimiento villenense del Peñón de la Zorra han proporcionado ya varias dataciones sobre muestras de vida corta, que constituyen las primeras fechas radiocarbónicas -todavía inéditas- para el Campaniforme del Alto Vinalopó.

3. Durante el año 2013 se llevaron a cabo de nuevo excavaciones arqueológicas sistemáticas en este último yacimiento, que han permitido disponer de las primeras dataciones radiocarbónicas. Éstas, no obstante, no se incluyen en el modelo estadístico desarrollado para el presente estudio. Es de esperar que muy pronto se disponga de una serie de referencias cronológicas bien contextualizadas de este yacimiento, lo que nos permitirá continuar progresando en la consolidación de la propuesta cronológica que planteamos en este trabajo.

4. Las dos dataciones de la tumba del corte 11 -una del esqueleto y otra de un hueso de ovicaprino perteneciente al ajuar cárnico- 
además de diferir considerablemente en sus respectivos intervalos a $1 \sigma$ y $2 \sigma$, resultan más recientes que la que ha proporcionado el esqueleto de la tumba del corte 10 , estratigráficamente superpuesta a la anterior. El hecho de que sólo una de las cuatro muestras enviadas para datar el esqueleto de la tumba del Corte 11 conservara colágeno suficiente para realizar la datación nos hace creer que los restos óseos se encuentran afectados por ácidos húmicos que han rejuvenecido las dos fechas obtenidas.

5. Otras dos fechas -Beta-258465, y Beta-287334- pertenecen a contextos de los siglos VIII y IX d.C., fuera de los límites cronológicos planteados para este trabajo.

6. La datación Beta-268981 se obtuvo de una muestra ósea incluida en el preparado del pavimento inicial de una de las viviendas. Sin embargo, la datación obtenida situaba este evento en un horizonte cronológico básicamente pre-argárico, incoherente con el registro artefactual asociado y claramente disonante en relación al resto de dataciones referidas a la fase I. Desde el primer momento se sospechó que tal discrepancia podría deberse a las particulares características de la muestra datada: un caparazón de tortuga de agua-Clemmys caspica leprosa- que debido al entorno lagunar e incluso marismeño en el que en época prehistórica se encontraba el Cabezo Pardo, podría haberse visto afectado por el efecto reservorio marino, circunstancia que no fue convenientemente advertida al laboratorio Beta Analytic. La aplicación de la curva Intcal13 para la calibración de la fecha radiocarbónica convencional no habría proporcionado una adecuada corrección de la misma. En cambio, al realizar la calibración con la curva Marine13 el resultado arrojaba unos valores perfectamente coherentes con la datación Beta-287332, obtenida de un contexto estratigráficamente contemporáneo, de manera que hemos tomado la decisión de incluirla en la serie radiocarbónica asumiendo los valores proporcionados por su calibración con la curva Marine13.

7. Agradecemos a Sergio Martínez Monleón la cesión de la datación, así como la realización de alguno de los mapas y gráficas que ilustran este artículo.

8. A diferencia de Terlinques y Cabezo Pardo, las dataciones de Cabezo Redondo se han incluido en el modelo sin atender a su ordenación estratigráfica, de manera que el intervalo considerado en su caso está referido al lapso temporal comprendido entre la ocupación inicial del asentamiento y su definitivo abandono.

9. Agradecemos a Rubén Cabezas Romero, los datos facilitados sobre el Cabezo de la Escoba, desarrollados en el marco del Trabajo fin de Máster del Máster oficial de Arqueología profesional y Gestión del Patrimonio de la Universidad de Alicante, en el curso académico 2013-14.

\section{BIBLIOGRAFÍA}

ACOSTA, G. (1999): Procesos de trabajo determinado. La configuración de modos de trabajo en la cultura arqueológica, Boletín de Antropología Americana, 35, 5-21.

ALONSO F.; RODRÍGUEZ TROBAJO, E.; RUBINÓS, A. (2004): Datación de madera constructiva en San Pedro de la Nave (Zamora) y su interdatación con San Juan de Baños (Palencia), La iglesia de San Pedro de la Nave (Zamora). Instituto de Estudios Zamoranos "Florián de Ocampo", Zamora, 209-237.
ARANDA, G.; LOZANO, A. (2014): The chronology of megalithic funerary practices: a Bayesian approach to Grave 11 at El Barranquete necropolis (Almería, Spain), JAS 50, 369-382.

ARTEAGA, O. (2000): La sociedad clasista inicial y el origen del estado en el territorio de El Argar, Revista Atlántico-Mediterránea de Arqueología Social 3, 121-219.

BARCIELA, V.; HERNÁNDEZ PÉREZ, M. S.; LÓPEZ SEGUÍ, E.; TORREGROSA, P. (2012): A medio camino. Excavaciones arqueológicas en El Negret (Agost, Alicante), Marq, Arqueología y museos, 05, 103-131.

BATE PETERSEN, F. (1998): El proceso de investigación en arqueología, Crítica, Barcelona.

BAYLISS, A.; BRONK RAMSEY, C.; VAN DER PLICHT, J.; WHITTLE, A. (2007): Bradshaw and Bayes: Towards a Timetable for the Neolithic, Cambridge Archaeological Journal 17,1 Supplement, 1-28. DOI: http://dx.doi.org/10.1017/S0959774307000145

BAYLISS, A. (2009): Rolling out revolution: using radiocarbon dating in archaeology, Radiocarbon 51, 1, 123-147.

BECK Jr., R.; DOUGLAS, J.; JAMES, A. B.; TIMOTHY, K. E. (2007): Eventful archaeology: the place of space in structural transformation, Current Anthropology 48, 6, 833-860. DOI: http://dx.doi.org/10.1086/520974

BERNABEU, J. (1984): El vaso campaniforme en el País Valenciano, Trabajos Varios del Servicio de Investigaciones Prehistóricas, 80, Diputación Provincial, Valencia.

BOAVENTURA, R.; MATALOTO, R. (2013): Entre mortos e vivos: nótulas acerca da cronologia adsoluta do Megalitismo do Sul de Portugal, Revista Portuguesa de Arqueologia 16, 81-101.

BOLENDER, D. J. (2010): Toward an eventful archaeology, Eventful archaeologies: new approaches to social transformation in the archaeological record, (D. J. Bolender, Ed.), IEMA Proceedings, vol. 1. State University of New York, Albany, 3-14.

BRONK RAMSEY, C. (1994): Analysis of chronological information and radiocarbon calibration: the program OxCal, $\mathrm{Ar}$ chaeological Computing Newsletter 41, 11-16.

BRONK RAMSEY, C. (2009): Bayesian analysis of radiocarbon dates, Radiocarbon 51, 1, 337-360.

BUCK, C.E. (2003): Bayesian chronological data interpretation: where now?, Tools for constructing chronologies: crossing disciplinary boundaries (C. E. Buck, A.R. Millard, eds.), London, 1-24.

BUCK, C. E.; CAVANAGH, W. G.; LITTON, C. D. (1996): The Bayesian approach to interpreting archeological data, Wiley, Chichester.

BUCK, C. E.; CHRISTEN, J. A.; JAMES, G. N. (1999): Bcal: an on-line Bayesian radiocarbon calibration tool, Internet archaeology 7 (http: intarch.ac.uk/journal/issue7/buck/).

BURILLO, F.; PICAZO, J. (1997): El sistema ibérico turolense durante el segundo milenio a.C., SAGVNTVM-PLAV 30, 29-58. 
CASTRO, P. V.; LULL, V.; MICÓ, R. (1996): Cronología de la Prehistoria Reciente de la Península Ibérica y Baleares (c. 2800-900 cal ANE), BAR International Series 652, Oxford.

CHAPMAN, R. (1991): La formación de las sociedades complejas. El Sureste de la Península Ibérica en el marco del Mediterráneo Occidental, Barcelona.

COLOMINAS, J. (1936): La necròpolis de "Las Laderas del Castillo" (Callosa de Segura, provincia d'Alacant, AIEC VIII, 33-39.

EIROA, J. J.; LOMBA, J. (1997-98): Dataciones absolutas para la Prehistoria de la Región de Murcia. Estado de la cuestión, APAUM 13-14, 81-118.

FERNÁNDEZ-POSSE, M. D.; GILMAN, A.; MARTÍN, C. (1996): Consideraciones cronológicas sobre la Edad del Bronce en La Mancha, Complutum Extra 6, 2,111-138.

FURGÚS, J. (1937): Col.lecció de treballs del P.J.Furgús. Trabajos Varios del Servicio de Investigación Prehistórica de Valencia, 5 , Valencia.

GELMAN, A.; CARLIN, J. B.; STERN, H. .; RUBIN, D. B. (2004): Bayesian data analysis, Boca Raton, Chapman and Hall/ CRC, 2nd Edition.

GILMAN, A. (2003): El impacto del radiocarbono sobre el estudio de la Prehistoria tardía de la Península Ibérica: breves comentarios, $T P$ 60, 2, 7-13.

GONZÁLEZ MARCÉN, P. (1994): Cronología del grupo argárico, Revista d'Arqueologia de Ponent 4, 7-46.

GONZÁLEZ PRATS, A. (1983): Estudio arqueológico del poblamiento antiguo de la Sierra de Crevillente, Anejo I de Lucentum, Alicante.

GONZÁLEZ PRATS, A. (1986): La Penya Negra V. Excavaciones en el poblado del Bronce Antiguo y en el recinto fortificado ibérico (campaña de 1982), NAH 27, 145-263.

GONZÁLEZ PRATS, A. (1990): Nueva luz sobre la protohistoria del Sudeste, Universidad de Alicante.

GONZÁLEZ PRATS, A.; RUÍZ SEGURA, E. (1995): Urbanismo defensivo de la Edad del Bronce en el Bajo Vinalopó. La fortificación argárica de Caramoro I (Elche, Alicante), Estudios de vida urbana 2, 85-107.

GUSI, F.; OLÀRIA， C. (1995): Cronologies absolutes en l'arqueologia del País Valencià, Actes de les Segones Jornades d'Arqueologia ( $\mathrm{R}$. Enguix, ed.), Alfàs del Pi, 1994,119-148.

HERNÁNDEZ PÉREZ, M. S. (1986): La cultura de El Argar en Alicante. Relaciones temporales y espaciales con el mundo del Bronce Valenciano, Homenaje a Luis Siret 1934-1984, Cuevas de Almanzora, 1984, Conserjería de Cultura, Sevilla, 341-350.

HERNÁNDEZ PÉREZ, M. S. (1997): Espacio y tiempo en la Edad del Bronce del País Valenciano, Espacio, Tiempo y Forma, Serie I, Prehistoria y Arqueología, 10, 279-315.

HERNÁNDEZ PÉREZ, M. S. (2003): Mirando hacia el Sureste. A propósito de la Edad de los Metales, Estudios de Arqueología dedicados a la profesora Ana María Muñoz Amilibia, (S. Ramallo, ed.), Murcia, 43-56.
HERNÁNDEZ PÉREZ, M. S. (2009a): Entre el medio y el Bajo Vinalopó. Excavaciones arqueológicas en el Tabayá (Aspe, Alicante) 1987-1991, En los confines del Argar. Una cultura de la Edad del Bronce en Alicante (M.S. Hernández, J.A. López y J.A. Soler, Eds.), Alicante, 292-305.

HERNÁNDEZ PÉREZ, M. S. (2009b): Tiempos de cambio. El final del Argar en Alicante, En los confines del Argar. Una cultura de la Edad del Bronce en Alicante (M.S. Hernández, J.A. López y J.A. Soler, eds.), Alicante, 292-305.

HERNÁNDEZ PÉREZ, M. S. (2012): El Cabezo Redondo (Villena, Alicante) y el Bronce Tardío en las tierras meridionales valencianas, Cogotas I: La cultura de la Edad del Bronce en la Península Ibérica, Homenaje a Ma Dolores Fernández Posse (J.A. Rodríguez y J. Fernández, coords.), Valladolid, 111-146.

HERNÁNDEZ PÉREZ, M. S.; JOVER, F. J.; LÓPEZ PADILLA, J. A. (2013): The social and political situation between 1750 and $1500 \mathrm{cal}$ BC in the central Spanish Mediterranean: an archaeological overview, 1600 Cultural change in the shadow of the Thera-Eruption? (H. Meller, F. Bertemes, H.-R. Bork, H. Meller y R. Risch, eds.), Tagunden des Landmuseums für Vorgeschichte Halle, band 9, Halle, 303-314.

HERNÁNDEZ PÉREZ, M. S.; LÓPEZ PADILLA, J. A. (2010): La mort a l'Argar alacantí. El Tabaià com a paradigma, Restes de vida. Restes de mort. La mort en la Prehistòria (A. Pérez, B. Soler, eds.), Valencia, 221-228.

HERNÁNDEZ PÉREZ, M. S.; SIMÓN, J. A.; LÓPEZ MIRA, J. A. (1994): Agua y poder. El cerro del Cuchillo (Almansa, Albacete), Patrimonio Histórico-Arqueología, 9, 218, Toledo.

JOVER, F. J. (1999): Una nueva lectura del "Bronce Valenciano", Universidad de Alicante, Alicante.

JOVER, F. J.; LÓPEZ PADILLA, J. A. (1997): Arqueología de la muerte. Prácticas funerarias en los límites de El Argar. Universidad de Alicante, Alicante.

JOVER, F. J.; LÓPEZ PADILLA, J. A. (1999): Campesinado e Historia. Consideraciones sobre las comunidades agropecuarias de la Edad del Bronce en el Corredor del Vinalopó, APL XXIII, 233-257.

JOVER, F. J.; LÓPEZ PADILLA, J. A. (2004): 2110-1200 BC. Aportaciones al proceso histórico en la cuenca del río Vinalopó, La Edad del Bronce en tierras valencianas y zonas limítrofes (L. Hernández, M.S. Hernández, eds.), Instituto de Cultura Juan Gil-Albert, Ayuntamiento de Villena, Alicante, 285-302.

JOVER, F. J.; LÓPEZ PADILLA, J. A. (2005): Barranco Tuerto y el proceso histórico en el corredor del Vinalopó durante el II milenio $B C$, Serie Vestigium, 1, Museo Arqueológico, Villena.

JOVER, F. J.; LÓPEZ PADILLA, J. A. (2009a): Miquel Tarradell y José María Soler: la revolución radiocarbónica y la Edad del Bronce en la península Ibérica, Pyrenae 40, 2, 79-103.

JOVER, F. J.; LÓPEZ PADILLA, J. A. (2009b): Más allá de los confines de El Argar. Los inicios de la Edad del Bronce y la delimitación de las áreas culturales en el cuadrante suoriental de la península Ibérica, 60 años después, En los confines del 
RAdiocarbono y estadística bayesiana: APORTACIONES A la CRONOLOGía de LA EDAD DEL BRONCE EN EL EXTREMO ORIENTAL DEL SUDESTE DE LA PENÍNSULA IBÉRICA

Argar. Una cultura de la Edad del Bronce en Alicante (M.S. Hernández, J.A. López, J.A. Soler, eds.), MARQ, Alicante, 268-291

JOVER, F. J.; LÓPEZ PADILLA, J. A. (2011): La observación en el estudio de la Edad del Bronce en tierras valencianas. Del ensalzamiento del "objeto" y la revolución radiocarbónica al necesario reencuentro con la estratigrafía, QPAC 29, 209-229.

JUAN-CABANILLES, J. (2005): Las manifestaciones del campaniforme en el País Valenciano. Una visión sintética, El Campaniforme en la península Ibérica y su contexto europeo (M. Rojo-Guerra, R. Garrido-Pena, I. García-Martínez de Lagrán, eds.), Universidad de Valladolid, Valladolid, 389-410.

JUAN-CABANILLES, J.; MARTÍNEZ VALLE, R.; BADAL, E.; OROZCO, T.; VERDASCO, C. (2005): Un aprisco bajo abrigo en el yacimiento eneolítico de "El Cinto Mariano" (Requena, Valencia), Actas del III Congreso del Neolítico en la Península Ibérica (P. Arias; R. Ontañón, R. y C.García, Coords.), Santander, 2003, 167-174.

LEE, P. M. (2004): Bayesian statistics . An introduction, Hodder Arnold, London.

LLOBREGAT, E. (1971): Eine siedlung des "Bronce Valenciano" auf der Serra Grossa (Prov. Alicante), MM 12, 87-100.

LÓPEZ AGUILAR, F. (1990): Elementos para una construcción teórica en arqueología, Colección científica, 191, INAH, México.

LÓPEZ PADILLA, J. A. (2006): Consideraciones en torno al Horizonte Campaniforme de transición, APL XXVI, 193-243.

LÓPEZ PADILLA, J. A. (2009): El grupo argárico en los confines orientales del Argar, En los confines del Argar. Una cultura de la Edad del Bronce en Alicante (M.S. Hernández, J.A. López, J.A. Soler, eds.), MARQ, Alicante, 247-267.

LÓPEZ PADILLA, J. A. (2011): Asta, hueso y marfil. Artefactos óseos de la Edad del Bronce en el Levante y Sureste de la península Ibérica (c. 2500-1300 cal BC), Serie Mayor 9, MARQ, Alicante.

LULL, V. (1983): La “Cultura de El Argar”. Un modelo para el estudio de las formaciones económico sociales prehistóricas, Madrid.

LULL, V.; MICÓ, R.; RISCH, R.; RIHUETE, C. (2009): El Argar: la formación de una sociedad de clases, En los confines del Argar. Una cultura de la Edad del Bronce en Alicante (M.S. Hernández, J.A. López, J.A. Soler, eds.), MARQ, Alicante, 224-245.

LULL, V.; MICÓ, R.; RIHUETE, C.; RISCH, R., (2010): Límites históricos y limitaciones del conocimiento arqueológico: la transición entre los grupos arqueológicos de Los Millares y El Argar, Arqueología, sociedad, territorio y paisaje, Homenaje a $M^{a}$ Dolores Fernández Posse (P. Bueno, A. Gilman, C. Martín, F.J. Sánchez Palencia, eds.), Madrid, 75-94.

LULL, V.; MICÓ, R.; RIHUETE, C.; RISCH, R. (2011): El Argar and the Beginning of Class Society in the Western Mediterranean, Sozialarchäologische Perspektiven: Gesellschaftlicher Wandel 5000-1500 v.Chr. zwischen Atlantik und Kaukasus (S. Hansen, J. Müller, eds.), Deutsches Archäologisches Institut, Von Zabern, Berlin, 381-414.
LULL, V.; MICÓ, R.; RIHUETE, C.; RISCH, R. (2013a): Funerary practices and kinship in an Early Bronze Age society: a Bayesian approach applied to the radiocarbon dating of Argaric double tombs, JAS 40/12, 4626-4634.

LULL, V.; MICÓ, R.; RIHUETE, C.; RISCH, R. (2013b): Political collaps and social change at the end of El Argar, $1600 \mathrm{Cul}$ tural change in the shadow of the Thera-Eruption? $(\mathrm{H}$. Meller, F. Bertemes, H.-R. Bork, H. Meller, R. Risch, eds.), Landesmuseum für Vorgeschichte 9, Halle, 283-302.

LULL, V.; MICÓ, R.; RIHUETE, C.; RISCH, R. (2014): The La Bastida fortification: new light and new questions on early Bronze Age societies in the western Mediterranean, Antiquity 88, 395-410.

LUNN, D. J.; THOMAS, A.; BEST, N.; SPIEGELHALTER, D. (2000): WinBUGS. A Bayesian modeling framework: concepts, structure an extensibility, Statistics and computing 10, 325-337. DOI: http://dx.doi.org/10.1023/A:1008929526011

MARTÍNEZ RODRÍGUEZ, A. (1997): Excavaciones de urgencia en la calle Carril de Caldereros, Edificio Plaza Real, ${ }^{\circ} 1$ (Lorca), Memorias de Arqueología de la Región de Murcia 6, 313-362.

MARTÍNEZ RODRÍGUEZ, A. (1999): Desde nuestros lejanos antepasados hasta época romana, Lorca histórica. Historia, Arte y Literatura (J.F. Jiménez, coord.), Murcia, 19-59

MARTÍNEZ RODRÍGUEZ, A.; PONCE GARCÍA, J. (2002): Excavación arqueológica de urgencia en el subsuelo de la antigua Iglesia del convento de las Madres Mercedarias (C/ Zapatería - C/ Cava, Lorca), 1996, Memorias de Arqueología de la Región de Murcia 10,90-137.

MATALOTO, R.; BOAVENTURA, R. (2012): Entre vivos e mortos nos IV e III milénios a.n.e. do Sul de Portugal: um balanço relativo do povoamento com base em datações pelo radiocarbono, Revista Portuguesa de Arqueologia, 12,2, 31-77.

MENÉNDEZ, J.; FLORSCHUTZ, F. (1961): Resultado del análisis polínico de una serie de muestras de turba recogida en la Ereta del Pedregal (Navarrés, Valencia), APL IX, 97-100.

MILLARD, A. R. (2005): What can Bayesian statistics do for archaeological predictive modelling?, Predictive modeling for archaeological heritage management: a research agen$d a$ (P.M. Van Leusen, H. Kamermans, eds.), Nederlandse Archeologische Rapporten 29, 169-182.

MOLINA, F. (1978): Definición y sistematización del Bronce Tardío y Final en el Sureste de la Península Ibérica, CPAUG 3, 159-232.

MOLINA, F.; CÁMARA, J. A. (2009): La cultura argárica en Granada y Jaén, En los confines del Argar. Una cultura de la Edad del Bronce en Alicante (M.S. Hernández, J.A. López, J.A. Soler, eds.), MARQ, Alicante, 196-223.

NIETO, G.; CLEMENTE, J. (1983): El cerro de la Campana y su cronología según el C-14 (Yecla, Murcia), XVI CNA (Cartagena, 1982), Zaragoza, 295-309. 
PASCUAL-BENITO, J. LL.; BERNABEU, J.; PASCUAL BENEYTO, J. (1993): Los yacimientos y las estructuras, El III milenio a.C. en el País Valenciano. Los poblados de Jovades (Cocentaina) y Arenal de la Costa (Ontinyent) (J. Bernabeu, dir.), SAGVNTVM-PLAV 26, 25-46.

PÉREZ JORDÀ, G. (2013): La agricultura en el País Valenciano entre el VI y el I milenio a. C., Tesis Doctoral de Prehistoria, Universitat de València, recurso on-line: http://roderic. uv.es/handle/10550/31152

PÉREZ JORDÀ, G.; CARRIÓN MARCO, Y.; GARCÍA PUCHOL, O.; GÓMEZ PUCHE, M.; PASCUAL BERLANGA, G.; PASCUAL BENEYTO, J.; BERNABEU AUBÁN, J. (2011): Los trabajos de excavación, La Vital (Gandia, Valencia). Vida y muerte en la desembocadura del Serpis durante el III y el I milenio a.C. (G. Pérez Jordà, J. Bernabeu, Y. Carrión, O. García Puchol, LL. Molina, M. Gómez Puche, eds.), Trabajos Varios del SIP 113, Valencia, 17-34.

PÉREZ JORDÀ, G.; BERNABEU, J.; CARRIÓN MARCO, Y.; GARCÍA PUCHOL, O.; MOLINA, LL.; GÓMEZ PUCHE, M. (eds.) (2011): La Vital (Gandia, Valencia). Vida y muerte en la desembocadura del Serpis durante el III y el I milenio a.C, Trabajos Varios del SIP 113, Valencia.

PÉREZ RICHARD, E. S.; GALLARDO, J.; RAMOS, F.; ORTIZ, C.; MARTÍNEZ GARCÍA, J. J.; LÓPEZ MARTÍNEZ, C. M.; MARTÍ, E. M. (2008): Intervención arqueológica en la calle Cava, 16-17 de Lorca, Memorias de Arqueología de la Región de Murcia 15 (2000- 2003), 691- 703.

RENFREW, C. (1973): Before Civilization: the radiocarbon revolution and prehistoric Europe, London, Pimlico.

R CORE TEAM (2013): $R$ : A Language and Environment for Statistical Computing, Vienna, Austria.

REIMER, P. J.; BARD, E.; BAYLISS, A.; BECK, J. W.; BLACKWELL, P. G.; BRONK RAMSEY, C.; BUCK, C. E.; CHENG, H.; EDWARDS, R. L.; FRIEDRICH, M.; GROOTES, P. M.; GUILDERSON, T. P.; HAFLIDASON, H.; HAJDAS, I.; HATTÉ, C.; HEATON, T. J.; HOFFMANN, D. L.; HOGG, A. G.; HUGHEN, K. A.; KAISER, K. F.; KROMER, B.; MANNING, S. W.; NIU, M.; REIMER, R. W.; RICHARDS, D. A.; SCOTT, E. M.; SOUTHON, J. R.; STAFF, R. A.; TURNEY, C. S. M.; VAN DER PLICHT, J. (2013): IntCal13 and Marine13 Radiocarbon Age Calibration Curves 0-50,000 Years cal BP, Radiocarbon 55, 4, 1869-1887.

DOI: http://dx.doi.org/10.2458/azu_js_rc.55.16947

RISCH, R.; MELLER, H. (2013):Wandel und kontinuität und Europa im Mittelmeerraum um 1600 v. Chr., 1600 Cultural change in the shadow of the Thera-Eruption? (H. Meller; F. Bertemes, H.-R. Bork, H. Meller, R. Risch, eds.), Landesmuseum für Vorgeschichte, 9, Halle, 597-613.

ROBERT, C. P.; CASELLA, G. (2004): Monte Carlo Statistical methods, New York, Second Edition.

DOI: http://dx.doi.org/10.1007/978-1-4757-4145-2
RUBINÓS, A. (1999): Datación por carbono-14 del yacimiento de Santa María de Melque, AEA 72, nº 179-180, 220-226.

SCARRE, C. (2010): Rocks of Ages: Tempo and Time in Megalithic Monuments, EJA 13, 2, 175-193.

SCHIFFER, M. B. (1983): Toward the identification of formation processes, American Antiquity 48, 675-706. DOI: http://dx.doi.org/10.2307/279771

SCHIFFER, M. B. (1986): Radiocarbon dating and the "old wood" problem: the case of the Hohokam chronology, JAS 13, 13-30.

SCHIFFER, M. B. (1987): Formation processes of the archaeological record, University of Nuevo Mexico, Alburquerque.

SOLER DÍAZ, J. A.; PÉREZ JIMÉNEZ, R.; BELMONTE, D. (2006): Arquitecturas del agua en un punta al mar: a propósito de las estructuras de la Edad del Bronce que se identifican en la Illeta dels Banyets, El Campello, Alicante, La ocupación prehistória de la Illeta dels Banyets (J.A. Soler Díaz, ed.), Serie Mayor 5, MARQ, Alicante, 67-119.

SOLER DÍAZ, J. (2009): Los confines de El Argar en el registro arqueológico. Sobre la Illeta dels Banyets de El Campello, Alicante, En los confines del Argar. Una cultura de la Edad del Bronce en Alicante (M.S. Hernández, J.A. López, J.A. Soler, eds.), MARQ, Alicante, 170-189.

SOLER GARCÍA, J. M. (1987): Excavaciones arqueológicas en el Cabezo Redondo (Villena-Alicante), Instituto de Cultura Juan Gil-Albert, Alicante.

SOLER GARCÍA, J. M. ; FERNÁNDEZ MOSCOSO, E. (1970): Terlinques. Poblado de la Edad del Bronce en Villena (Alicante), SAGVNTVM-PLAV 10, 27-65.

STURZ, S.; LIGGES, U.; GELMAN, A. (2005): R2WinBUGS: a package for running WinBUGS from R, Journal of Statistical Software 12, 3, 1-16.

TARRADELL MATEU, M. (1963): El País Valenciano del Neolítico a la iberización. Ensayo de síntesis, Anales de la Universidad de Valencia XXXVI.

TARRADELL, M. (1970): Dos nuevas fechas de C-14 para Villena y Mallorca, SAGVNTVM-PLAV 10, 19-26.

TRELIS, J. (1992): Excavaciones en el yacimiento de la Edad del Bronce en el Mas del Corral (Alcoy, Alicante), Recerques del Museu d'Alcoi, 1, 85-89.

WALKER, J. M. (1981): El yacimiento prehistórico de Catí-Foradà, Petrel (Alicante), Revista del Instituto de Estudios Alicantinos 32, 87-89.

WHITTLE, A.; BARCLAY, A.; BAYLISS, A.; McFADYEN, L.; SCHULTING, R.; WYSOCKI, M. (2007): Building for the dead: Events, Processes and Changing Worldviews from the Thirty-eight to the Thirty-fourth Centuries cal. BC in Southern Britain, Cambridge Archaeological Journal 17,1, Supplement, 127-147.

WILLIAMS, A. N. (2012): The use of summed radiocarbon probability distributions in archaeology: a review of methods, JAS 39, 578-589. 